\title{
The Effect of New Technology on Energy Consumption
}

\author{
David Popp ${ }^{1}$ \\ The University of Kansas
}

August 21, 1998

\begin{abstract}
This paper uses patent data to estimate the effect of new technologies on energy consumption. A stock of energy knowledge is created for each of 13 energy-intensive industries. The median present value of long run savings from a new patent is nearly 9 million dollars. The results are used to simulate the effect of a ten-percent energy tax. Although factor substitution is found to play a greater role than induced innovation in the short run, the energy savings from induced innovation play a much larger role than factor substitution in the long run, due to the cumulative nature of research.

JEL Classifications: Q41Energy: Demand and Supply, O33 Technological Change: Choices and Consequences,

key words: energy; technology; induced innovation; patents; Yale Technology Concordance (YTC)

The author would like to thank William Nordhaus, Robert Evenson, Joel Waldfogel, Ariel Pakes and Deitrich Earnhart for useful comments. In addition, the help of Samuel Kortum, Jonathan Putnam, and Robert Evenson in obtaining patent data is gratefully acknowledged. Despite the worthy assistance of these individuals, all mistakes are solely the responsibility of the author. Partial funding for this paper was provided by U.S. Department of Energy grant \#593A3140217.
\end{abstract}

\footnotetext{
${ }^{1}$ Department of Economics, 213 Summerfield Hall, Lawrence, KS 66045-2113. Phone: (785) 864-3501. Fax: (785) 864-5270. E-mail: dpopp@ukans.edu.
} 
This paper uses data on energy patents to estimate the effect of new technology on industrial energy consumption. It is part of a broader study designed to ascertain the effect of energy prices on the development of technologies aimed at energy conservation or at providing new sources of energy. Earlier papers (Popp 1998a and b) have focused on the development of such technologies. Using patents as an indicator of technological change, Popp (1998a) demonstrates that energy prices do have a significant impact on the amount of energy-efficient innovative activity. Popp (1998b) uses patent citation data to demonstrate that returns to research tend to fall over time within each technological field.

In contrast, this paper focuses on the effect that these patents have on energy consumption. It makes use of the Yale Technology Concordance (YTC) to map energy patents to the industries in which they are used. These data are then used to construct stocks of energyefficient knowledge, which are used in estimating cost functions for various energy intensive industries.

The effect of new technologies on energy consumption has important policy implications. Many environmental policy proposals can be expected to lead to the development of new technologies. In fact, the Clinton administration made the development of more efficient technologies one of the cornerstones of its proposal for the 1997 Kyoto summit on climate change. Furthermore, environmental policy proposals often take aim at energy consumption. Examples include the Btu tax proposed by the Clinton administration in 1993 or the energy taxes advocated by many economists to slow the effects of global warming. As these policies increase the cost of energy, they will lead to the development of more energy-efficient technologies. Understanding the role that technology plays in energy-consumption is crucial to understanding the total impact of such policies. Towards this end, the paper concludes with a simulation of the 
effect of a 10 percent energy tax in six industries. The simulation is used to separate the effect of new technologies developed in response to the tax from simple factor substitution away from energy that occurs because of higher prices.

Knowledge of the impact of new energy technologies on energy consumption is also important for understanding recent trends in energy consumption and in making projections about future consumption. Energy intensity, defined as Btu of energy per dollar of output, fell dramatically during the late 1970's and early 1980s. Figure 1 shows this trend, along with the trend in energy prices since the 1970's. In both cases, the data are normalized so that $1982=100$. Before the first energy crisis, energy intensity remained relatively constant at about 20,000 Btu per dollar of output, using 1990 dollars. Energy intensity fell from 1974 to 1986, when it again leveled out, this time between 13,000 and 14,000 Btu per dollar output.

Price-induced substitution away from energy certainly played a role in the decline of energy intensity, but it does not tell the whole story. Real energy prices peaked in 1982 before beginning to fall. Yet, energy intensity continued to fall, and did not rise again, even though energy prices remained low. The lack of response can partially be explained by the costs of adjusting the capital stock. To improve energy efficiency, industries would need to install newer, more energy-efficient machines. This process takes time, as would removing them after energy prices fell. But technology must play a role as well. Even when energy prices returned to precrisis levels, energy intensity continued to fall. If the available technology had not changed, there would have been no reason for firms to make costly adjustments to capital after prices had fallen. Presumably they made these adjustments because the new technology, developed in response to the energy crisis, was better than the previously existing technology. This paper examines how changing technology influenced energy consumption. 


\section{Previous Literature}

This paper uses patent data to construct a stock of energy knowledge. These stocks are then used in a quadratic formulation of a restricted variable cost function to estimate the effect of new knowledge on energy consumption. As such, it borrows from two branches of previous economic literature. The first are previous studies of the effect on energy consumption over time. The present paper improves upon these studies by using patent data to more carefully measure technological progress. The second group of related work is studies of the productivity of R\&D. Using patent data offers improvements to this work as well. The following section describes previous work in both areas, and details how using patent data improves the results of each.

\section{A. Studies of Energy Consumption Across Time}

Studies of energy consumption across time began with a series of papers in the 1970's by authors such as Dale Jorgenson, Ernst Berndt, and David Wood. Typically, a flexible form cost or production function would be used to derive factor demand equations. In a series of papers in the 1970's, these authors investigated the demand for energy in American industries, using translog cost functions. ${ }^{1}$ Jorgenson was the first to introduce technological change into these models. Their paper, as well as those which follow, simply modeled technological change by including a time trend in the regressions. Jorgenson and Fraumeni (1981) use a time trend to represent technological change, and find that technological change was energy-using - that is, that energy use per unit output increased over time. Their paper, however, used data from 1958 to 1974. As shown in Popp (1998a), the two energy crises of the 1970's led to much innovation designed to save energy. Such technological change was not included in the data used by Jorgenson and Fraumeni. Thus, it is reasonable to expect that the results may be different today.

\footnotetext{
${ }^{1}$ See, for example, Berndt and Wood (1975) and Griffin and Gregory (1976).
} 
More recent work does find that technological change is energy saving. Berndt, Kolstad, and Lee (1993) estimate translog cost functions for manufacturing sectors in the United States, Canada, and France. They find that technological change leads to savings in both fuels and electricity. In a similar study, Mountain, Stipdonk, and Warren (1989) find that technological change in Ontario manufacturing industries is oil-saving and natural gas-using. Results for electricity use depended on the industry. The result that technology increases the consumption of natural gas occurs because natural gas prices were consistently low during the period studied in their paper. Sterner (1990) finds a positive rate of fuel saving technological progress in the Mexican cement industry, although most of the technological change is embodied in new types of capital. Finally, Berndt (1990) notes that gains in energy conservation usually lagged changes in energy prices. Industry was not merely substituting away from energy due to higher prices, but was investing in new technology that was less energy intensive. He also notes that the average quality of energy has increased as well. Firms are using more efficient sources of energy, such as electricity.

One feature common to all of the above papers is that they simply model technological change by introducing a time trend to their model. The use of a time trend has two drawbacks. One is that advances in energy-saving technology do not occur randomly over time, but are instead correlated with changes in energy prices. Thus, the results of these papers are sensitive to the time period studied. Technological advancements are energy-using when energy prices are low, and energy-saving when energy prices are high. Secondly, the time trend can only capture the overall impact of technological change. It can only tell us whether all of the technological advances that occurred during the period studied led to more or less energy use. For example, technological advances that lead to an increased reliance on capital might increase energy-use 
per unit output, as more energy would be required to run additional machines. However, the energy may be used more efficiently than before.

In both cases, the problem is that using a time trend makes it impossible to identify the effect of only those technologies that are related to energy consumption. For example, the Mountain, Stipdonk, and Warren paper finds that technological change was natural-gas using during the period studied. This occurred because natural gas prices were low during this period. As a result, new technologies tended to take advantage of low natural gas prices by using gas more than other energy sources. Nonetheless, there may have been technologies that improved the efficiency of natural gas use during the period studied. However, the effect of these innovations would not be identified in the study by Mountain et al. since it only captures the overall effect of technological change.

Using patents as an indicator of technological change, as is done in this paper, avoids these pitfalls. By identifying those patents that are related to energy efficiency, it is possible to identify the effect of technologies specifically related to energy consumption. In addition, using patent counts allows for fluctuations in the level of technological advancement over time. Energy prices and technological opportunities both play an important role in the direction of energysaving technological change. ${ }^{2}$ Patent data can identify both of these effects. Combining information on the development of new patents with information on the energy-savings resulting from new patents makes policy simulations possible.

\section{B. Studies of the Productivity of $R \& D$}

The second branch of literature related to this paper are studies that estimate the productivity of R\&D, such as those by Zvi Griliches, Frank Scherer and others during the

\footnotetext{
${ }^{2}$ See Popp (1998a,b) for studies examining the effect of energy prices on innovation.
} 
1980's. These papers use either firm or industry data to estimate production functions using R\&D expenditures as an input. Two different approaches are used. In the first, R\&D expenditures are used to create a stock of knowledge, usually by assuming a rate of depreciation of 15 percent on old R\&D. The equation to be estimated is of the form:

$$
\log Y=\alpha+\beta(\log X)+\gamma(\log K)+\varepsilon
$$

where $Y$ is output, $X$ are traditional inputs, such as labor and capital, and $K$ is the stock of knowledge, represented by $R \& D$ expenditures. The second approach uses growth rates to avoid the problem of constructing a stock of knowledge by using $R \& D$ as a measure of the change in the stock of knowledge. These studies estimate an equation of the form:

$$
\frac{\partial \log Y}{\partial t}=\alpha+\beta \frac{\partial \log X}{\partial t}+\gamma \frac{R}{Y}+\varepsilon
$$

where $R$ is a measure of $\mathrm{R} \& \mathrm{D}$ expenditures, and $R / Y$ is a measure of R\&D intensity. A survey of both types of studies can be found in Griliches (1995).

The results of these studies are mixed. Estimates of the rate of return to R\&D range from 0.2 to 0.5 . However, estimation of these equations, particularly those like equation (1) are complicated by the usual pitfalls of estimating production functions, such as simultaneity. For example, both Griliches and Jacques Mairesse (1984) and Philippe Cuneo and Mairesse (1984) find a correlation between firm R\&D and productivity across firms, but little correlation over time. These models are also handicapped in that they do not measure the spillovers from R\&D very well.

Finally, using R\&D expenditures as a measure of knowledge is problematic because we do not know the goal of the R\&D spending. R\&D expenditures can be divided into two broad categories: process innovations and product innovations. Process innovations are technological advances that improve the efficiency of production. Other innovations are product innovations. 
They either provide new products, or improve the quality of an existing product. Process innovations should affect the production function of the firm. Product innovations should not affect the production function, but do affect the quality of output. However, if the price indices used to normalize the value of output do not adequately account for improvements in the quality of output, the benefits of $R \& D$ affecting quality will be underestimated. To demonstrate this point, Scherer (1993) finds that estimates on the return to R\&D from 1973-89 falls from 0.36 to 0.13 when the computer industry is removed from his data set. Because of the rapid change in computer technology, the Bureau of Labor Statistics uses hedonic methods to construct price indices for the computer industry. However, it does not adjust the price indices of other industries for changes in quality.

This paper uses patent counts, rather than R\&D expenditures, as the measure of knowledge. Using patent counts as a measure of the stock of knowledge allows us to avoid some of the pitfalls encountered when using R\&D expenditures. The Yale Technology Concordance is used to identify the industry of manufacture and industry of use of patents. By sorting patents by their industry of use, we can be reasonably sure that the patents represent changes to the production process, rather than changes to the quality of output. Using patents assigned to the industry in which they are used ensures that the innovations represented in this paper are process innovations.

\section{Modeling}

R\&D is a dynamic process. The energy-savings resulting from a new innovation will be realized for years to come. In addition, the diffusion of benefits across firms in an industry takes time. As such, a dynamic model is needed for estimation. A normalized, restricted variable cost function (RVCF), described in Berndt, Morrison, and Watkins (1981) and Watkins and Berndt 
(1992), is used. The model allows for dynamic adjustment of quasi-fixed inputs. In this model, short-run demand equations of the variable inputs can be viewed as utilization equations, based on the current stock of quasi-fixed inputs.

\section{A. Theory}

Define the following variables. $\mathbf{v}=[L, E, M]^{\prime}$ is the vector of variable inputs used by a firm: labor, energy, and materials. $\mathbf{x}=\left[C, K_{E}, K_{O}\right]$ is the vector of quasi-fixed inputs available to the firm in any given period. $C$ is the stock of physical capital, $K_{E}$ is the stock of energy-related knowledge, and $K_{O}$ is the stock of other knowledge. Installing new capital is costly. Resources must be diverted from the production of output to installation. Due to these internal adjustment costs, variations in the level of quasi-fixed inputs, $\dot{\mathbf{x}}$, lower the amount of output produced for a given level of $\mathbf{v}$ and $\mathbf{x}$. Denoting output as $Y$, we can write the production function of the firm as:

$$
Y=F(\mathbf{v}, \mathbf{x}, \dot{\mathbf{x}}) .
$$

The knowledge stock is constructed by using a count of patents, $P A T_{i, t}$, over time. The subscript $i$ denotes the type of patent (energy or other) and the subscript $t$ represents time. Over time, the knowledge embodied in a patent becomes obsolete, as new and better inventions take its place. In addition, it takes time for the knowledge embodied in a new patent to spread throughout the economy. To construct the stock of knowledge, a rate of decay, represented by $\beta_{1}$, is used to capture the obsolescence of older patents. A rate of diffusion, $\beta_{2}$, is included to capture the flow of knowledge. Defining $s$ as the number of years before the current year, the stock of knowledge at time $t$ is written as:

$$
K_{i, t}=\int_{s=0}^{\infty} e^{-\beta_{1}(s)}\left(1-e^{-\beta_{2}(s+1)}\right) P A T_{i, s} d s .
$$

The rate of diffusion is multiplied by $s+1$ so that diffusion is not constrained to be zero in the current period. Since any change in knowledge must account for both decay and diffusion, the 
net change in a stock of knowledge over time is:

$$
\begin{aligned}
\dot{K}_{i, t} & =P A T_{i, t}\left(1-e^{-\beta_{2}}\right)+\frac{\partial K_{t-1}}{\partial t} \\
& =P A T_{i, t}\left(1-e^{-\beta_{2}}\right)+\int_{s=1}^{\infty}\left\{-\beta_{1} e^{-\beta_{1} s}\left(1-e^{-\beta_{2}(s+1)}\right)+\beta_{2} e^{-\beta_{1} s} e^{-\beta_{2}(s+1)}\right\} P A T_{i, s} d s
\end{aligned}
$$

In the short-run, firms minimize restricted variable costs, $G=\mathbf{w}^{\prime} \mathbf{v}$, where $\mathbf{w}^{\mathbf{\prime}}=[1$, $\left.p_{E} / w, p_{M} / w\right]$ is the vector of normalized variable input prices. The prices of inputs are given by the wage rate, $w$, and the price of energy and materials, $p_{E}$ and $p_{M}$, respectively. Restricted variable costs are minimized conditional on $\mathbf{w}, \mathbf{x}, \dot{\mathbf{x}}$, and $Y$. The result is the normalized restricted cost function (RVCF):

$$
G=G(\mathbf{w}, \mathbf{x}, \dot{\mathbf{x}}, Y)
$$

Write the normalized price of a variable input, $p_{j} / w$, as $\hat{p}_{j}$. In equilibrium, the partial derivative of the RVCF with respect to the normalized price of a variable input equals the shortrun cost-minimizing demand for $v_{j}$ :

$$
\frac{\partial G}{\partial \hat{p}_{j}}=v_{j}, \quad j=E, M
$$

Also, the partial derivative of $G$ with respect to the quantity of a quasi-fixed input, $x_{i}$, equals the negative of the normalized shadow cost of the quasi-fixed input:

$$
\frac{\partial G}{\partial x_{i}}=-u_{i}
$$

$u_{i}=q_{i}(r+\delta)$, where $q_{i}$ is the normalized acquisition price of the fixed input $i, r$ is the after-tax rate of return earned by the firm, and $\delta$ is the rate of depreciation of the capital stock.

The long-run problem faced by the firm is to minimize the present value of future costs,

$$
L(0)=\int_{0}^{\infty} e^{-r t}\left(G_{t}(\mathbf{w}, \mathbf{x}, \dot{\mathbf{x}}, Y)+\sum_{i=1}^{N} q_{i, t} z_{i, t}\right) d t
$$


where $z_{i}$ represents the gross change in the $i$ th capital stock. ${ }^{3}$ Berndt, Morrison, and Watkins (1982) show that the solution to this problem is:

$$
-G_{\mathbf{x}}-r G_{\dot{\mathbf{x}}}-\mathbf{u}+G_{\ddot{\mathbf{x}}} \ddot{\mathbf{x}}+G_{\mathbf{x} \dot{\mathbf{x}}} \dot{\mathbf{x}}=0,
$$

where the $\mathbf{x}$ and $\dot{\mathbf{x}}$ subscripts denote derivatives, and $\ddot{\mathbf{x}}$ is the second partial derivative of the capital stock vector with respect to time. By definition, the stock of quasi-fixed factors is at its optimal level in the steady state, implying that $\mathbf{x}=\mathbf{x}^{*}$ and $\dot{\mathbf{x}}=\ddot{\mathbf{x}}=0$. Subbing these equalities into (9) gives us the steady-state solution that defines the long-run optimal capital stocks:

$$
-G_{\mathbf{X}}\left(\mathbf{w}, \mathbf{x}^{*}\right)=\mathbf{u}+r G_{\dot{\mathbf{x}}}\left(\mathbf{w}, \mathbf{x}^{*}\right) .
$$

Equation (10) states that the marginal benefit to the firm of changing the stock of quasi-fixed inputs is equal to the marginal cost of a change in the level of the stock, where the marginal cost includes both the user cost and the marginal cost of adjustment.

To complete the model, equations (9) and (10) are used to derive an equation for the optimal accumulation of capital in each period. Treadway (1974) shows that the demands for the quasi-fixed factors can be generated from (9) and (10) as an approximate solution (in the neighborhood of $\mathbf{x}^{*}$ ) to the multivariate linear differential equation system:

$$
\dot{\mathbf{x}}=\mathbf{M} *(\mathbf{x} *-\mathbf{x}) .
$$

The matrix $\mathbf{M}^{*}$ is the adjustment matrix. It describes how quickly the firm moves from the current level of fixed inputs to the optimal level. Treadway shows that $\mathbf{M}^{*}$ satisfies the equation

$$
-G_{\dot{x} \dot{x}}^{*} \mathbf{M} *^{2}+r G_{\dot{x} \dot{x}}^{*} \mathbf{M} *-\left(G_{x x}^{*}+r G_{x \dot{x}}^{*}\right)=0 \text {. }
$$

By deriving equation (11), Treadway's work links the econometric factor demand model to the theoretical flexible accelerator model of investment.

\footnotetext{
${ }^{3}$ For the physical capital stock, the gross change in the capital stock, $\mathrm{z}_{\mathrm{C}}$, is simply $\dot{C}+\delta C$. The gross change of the knowledge stocks is given in equation (5).
} 
The solution to the firm's optimization problem is represented by the short-run variable factor demands, equation (7), and the optimal capital accumulation equation, (11). Ideally we would like to be able each of these equations. However, the amount of data available limits the number of parameters that can be estimated. Since the main focus of this paper is the effect of patents on energy consumption only the variable factor equations will be estimated in this paper.

\section{B. Estimation}

To proceed with estimation, a functional form must be provided for $G$. As in Watkins and Berndt, a quadratic approximation is used.

$$
\begin{aligned}
G & =L+p_{E} E+p_{M} M \\
& =Y\left[\alpha_{0}+\sum_{j=1}^{N} \alpha_{j} \hat{p}_{j}+\frac{1}{2} \sum_{j=1}^{N} \alpha_{i j} \hat{p}_{j}^{2}+\sum_{j=1}^{N} \sum_{k \neq j} \alpha_{j k} \hat{p}_{j} \hat{p}_{k}\right]+ \\
& \sum_{i=1}^{M} \alpha_{i} x_{i}+\frac{1}{2} \sum_{i=1}^{M} \alpha_{i i} \frac{x_{i}^{2}}{Y}+\sum_{i=1}^{M} \sum_{j=1}^{N} \alpha_{j i} x_{i} \hat{p}_{j}+\sum_{i=1}^{M} \sum_{k \neq i} \alpha_{i k} \frac{x_{i} x_{k}}{Y}+ \\
& \sum_{i=1}^{M} \phi_{i} \dot{x}_{i}+\frac{1}{2} \sum_{i=1}^{M} \phi_{i i} \frac{\dot{x}_{i}^{2}}{Y}+\sum_{i=1}^{M} \sum_{j=1}^{N} \phi_{j i} \dot{x}_{i} \hat{p}_{j}+\sum_{i=1}^{M} \sum_{k \neq i} \phi_{i k} \frac{\dot{x}_{i} \dot{x}_{k}}{Y}+\sum_{i=1}^{M} \sum_{k=1}^{M} \gamma_{i k} \frac{x_{i} \dot{x}_{k}}{Y}
\end{aligned}
$$

where $\hat{p}_{j}$ is the normalized price of the $j$ th input (energy or materials), $x_{i}$ is the level of the $i$ th capital stock, and $\dot{x}_{i}$ is the change in this capital stock.

The corresponding short-run factor demand equations are:

$$
\begin{aligned}
\frac{E}{Y}= & \alpha_{E}+\alpha_{E E} \hat{p}_{E}+\alpha_{E M} \hat{p}_{M}+\alpha_{E C} \frac{C}{Y}+\phi_{E \dot{C}} \frac{\dot{C}}{Y}+ \\
& \alpha_{E K_{E}} \frac{K_{E}}{Y}+\phi_{E \dot{K}_{E}} \frac{\dot{K}_{E}}{Y}+\alpha_{E K_{O}} \frac{K_{O}}{Y}+\phi_{E \dot{K}_{O}} \frac{\dot{K}_{O}}{Y} \\
\frac{M}{Y}= & \alpha_{M}+\alpha_{E M} \hat{p}_{E}+\alpha_{M M} \hat{p}_{M}+\alpha_{M C} \frac{C}{Y}+\phi_{M \dot{C}} \frac{\dot{C}}{Y}+ \\
& \alpha_{M K_{E}} \frac{K_{E}}{Y}+\phi_{M \dot{K}_{E}} \frac{\dot{K}_{E}}{Y}+\alpha_{M K_{O}} \frac{K_{O}}{Y}+\phi_{M \dot{K}_{O}} \frac{\dot{K}_{O}}{Y}
\end{aligned}
$$




$$
\begin{aligned}
\frac{L}{Y}= & \frac{G}{Y}-\frac{P_{E} E}{Y}-\frac{P_{M}}{Y}=\alpha_{0}-\frac{1}{2}\left(\alpha_{E E} \hat{p}_{E}^{2}+2 \alpha_{E M} \hat{p}_{E} \hat{p}_{M}+\alpha_{M M} \hat{p}_{M}^{2}\right)+ \\
& \sum_{i=1}^{M} \alpha_{i} \frac{x_{i}}{Y}+\frac{1}{2} \sum_{i=1}^{M} \alpha_{i i} \frac{x_{i}^{2}}{Y^{2}}+\sum_{i=1}^{M} \sum_{k \neq i} \alpha_{i k} \frac{x_{i} x_{k}}{Y}+ \\
& \sum_{i=1}^{M} \phi_{i} \frac{\dot{x}_{i}}{Y}+\frac{1}{2} \sum_{i=1}^{M} \phi_{i i} \frac{\dot{x}_{i}^{2}}{Y^{2}}+\sum_{i=1}^{M} \sum_{k \neq i} \phi_{i k} \frac{\dot{x}_{i} \dot{x}_{k}}{Y}+\sum_{i=1}^{M} \sum_{k=1}^{M} \gamma_{i k} \frac{x_{i} \dot{x}_{k}}{Y^{2}}
\end{aligned}
$$

\section{Net versus Gross Investment}

Before proceeding, it is necessary to distinguish between net and gross investment models, as outlined by Watkins and Berndt (1992). Net investment is investment that adds to the capital stock, rather than simply replacing depreciated capital. Gross investment includes new investments that add to the capital stock and investment that only aims to replace depreciating capital. Defining gross investment in the $i$ th capital stock as $z_{i}$, and net investment as $\dot{x}_{i}$, we see that gross investment is the sum of net investment and replacement investment:

$$
z_{i}=\dot{x}_{i}+\frac{\partial x_{i}}{\partial t}
$$

For physical capital, equation (17) simplfies to

$$
z_{C}=\dot{x}_{C}-\delta C
$$

For knowledge capital, the last term of equation (17) is replaced by equation (5).

In the steady state, all inputs are at their optimal level. As a result, net investment is equal to zero. Gross investment, $z_{i}$, is equal to replacement investment only. That is, the only investment that occurs in the steady state is investment that replaces depreciated capital. The net investment model assumes that this replacement investment is frictionless. It has no effect on costs in the steady state. The assumptions of the net investment model imply that the coefficients 
on $\dot{x}_{i}$ in the restricted variable cost function, (13), are equal to zero. ${ }^{4}$ Conversely, the gross investment model assumes that there are adjustment costs to replacement investment. Thus, even in the steady state, the costs of investment must be accounted for, since replacement investment is still necessary.

As noted by Watkins and Berndt (1992), the assumption of frictionless replacement investment of physical capital is not supported by economic theory. As such, the gross investment assumption will be made for the capital stock. However, the net investment assumption does make sense for the stock of knowledge. To see this, consider why the need for replacement investment arises. In the steady state, net investment is zero. Steady-state replacement investment occurs because the existing capital stock is decaying. Although the theoretical model outlined in this paper allows the knowledge stock to decay over time, this is merely a simplification for estimation purposes. In reality, it is not time itself that makes knowledge obsolete. Rather, the replacement of old knowledge with new and improved knowledge makes the old knowledge obsolete. Thus, the creation of new patents makes old patents obsolete. Schumpter referred to this process as "creative destruction." However, in the steady state, there is no desire for a net increase in knowledge, since the knowledge stock is, by definition of the steady state, at its optimal level. Thus, there is no demand for new patents. If new patents aren't being created, the old knowledge will not decay. Thus, constraining the coefficients on $\dot{x}_{i}$ to zero seems reasonable for the stock of knowledge parameters. ${ }^{5}$

\footnotetext{
${ }^{4}$ Algebraically, this is to ensure that marginal adjustment costs, defined by $\frac{\partial G}{\partial \dot{x}_{i}}$, are equal to zero in the steady

state. This requires that all coefficients on $\dot{x}_{i}$ be equal to zero except for $\varphi_{i i}$, the coefficient on $\frac{x_{i}^{2}}{Y}$.

5 In addition to being theoretically justifiable, using the net investment model for knowledge is important for calculating the value of energy savings resulting from a new patent later in the paper.
} 


\section{Data}

To estimate equations (14), (15), and (16), data on inputs, prices, $R \& D$, and knowledge are needed. Data for the first two are taken from the NBER Manufacturing Productivity Database. Patent data are used to construct the stocks of knowledge. To do this, we not only need data on the number of innovations in a given year, but also information on which industries make use of these innovations. The Yale Technology Concordance provides this information. R\&D data are available from the National Science Foundation (NSF), but not at the level of detail needed for this paper. However, the patent data can be combined with the R\&D data that is published by the NSF to get the R\&D expenditure data needed for this study. This section describes each component of the data in greater detail.

\section{A. Energy Patents by Industry - The Yale Technology Concordance}

To use patents as a measure of the knowledge available to a firm, we need to know which industries use which patents. Finding this information can be problematic. The U.S. Office of Technology Assessment and Forecast (OTAF) has developed a concordance between U.S. patents and industries, but several problems have been found with it. When a patent is granted, it is assigned to a technology class and subclass. The OTAF concordance assigns patents from each subclass to an industry of use. However, if there is more than one industry that would be reasonably considered to use the patents of a certain subclass, the patents were assigned to all of the industries. This method led to serious double counting and surprising discrepancies in the data. For example, motor engines were assigned to both the airline and motor vehicle industries. During a patenting boom by the Japanese automotive industry, the concordance assigned the patents to both Japan's auto and airline industries. Because the Japanese airline industry was so small, the auto patents dominated, and it appeared that the airline industry was experiencing a technological boom as well. (Griliches 1990) 
The Yale Technology Concordance (YTC) uses actual patent data to develop a more accurate concordance. ${ }^{6}$ When a patent is granted in Canada, it is not only assigned to a technology classification, but also given an industry of use and industry of manufacture, using the Canadian Standard Industrial Classification System (CSIC). Since a patent examiner makes these classifications, we can be confident that the assigned industries are related to the patent in question, since each examiner is an expert in his or her technology field. Using the actual Canadian data, the YTC authors develop a probability distribution of possible industries to which a patent in a given technology field may be assigned. The distribution can then be applied to patents in other countries. By developing the distribution, the YTC authors avoid the problem of double counting which occurs in the OTAF concordance. For example, in the scenario of the Japanese engines described above, the concordance might assign 90 percent of engine patents to autos, and 10 percent of engine patents to the airline industry.

In this paper, the Yale Technology Concordance is used to develop both a stock of energy knowledge and a stock of other knowledge for U.S. industries. Because Canada uses the International Patent Classification, it is first necessary to develop a list of IPC patent classifications related to energy consumption. Both classifications related to energy supply and classifications related to energy demand are used. These are listed in table $1 .^{7}$

The next step is to find the industry of use for these patent classes. This is done using the

\footnotetext{
${ }^{6}$ For more information on the Yale Technology Concordance, see Evenson et al. (1991) and Kortum and Putnam (1989, 1997).

${ }^{7}$ The list is similar to the list of U.S. classifications used in Popp (1998a,b). However, for some technologies, such as insulated windows, it was impossible to find a corresponding IPC classification. In addition, additional technologies, such as combustion, have been added. The added classifications are ones that have some energy saving benefit, but also other uses. Ambiguous classes were not included in the earlier papers, because the goal there was to estimate the effect of energy prices on patent counts. For example, a combustion patent may lead to a more efficient engine, or it may lead to a more powerful engine. In addition, combustion patents related to efficiency were influenced not only by energy prices, but fuel economy regulations in the U.S. These factors would have complicated the regressions in the earlier papers. However, for this estimation, as long as the patents have some energy-savings benefit, that effect can be identified in the data.
} 
concordance. Four-digit CSIC codes are used. Only industries that made significant use of the energy patents are considered. There are many instances of industries that had one or two patents from a particular class assigned to them. Such industries are not included in this paper. Industries for which the patents were obviously product, rather than process, inventions are also dropped. In addition, because the YTC gives results for the 1980 Canadian Standard Industrial Classification System and the industries in the NBER Manufacturing Productivity Database are classified by the 1972 U.S. SIC codes, it is necessary to map the Canadian industries into the corresponding U.S. industries. As Canadian industries are typically smaller, there are often two or three U.S. industry codes corresponding to a single Canadian industry code. In addition, since there is frequently a partial correlation among codes, it is often necessary to group two or three similar Canadian industries into a group, and then find the corresponding group of American industries. The results are a list of 13 industry groups used in this paper. The industry groups, along with their Canadian and U.S. SIC codes, are presented in table 2.

Next, using the concordance, the number of energy patents used in each of the 13 industry groups is calculated. Annual patent data from 1918 to 1991 are used. Table 3 shows the IPC classifications of the energy patents used most in the various industry groups, along with the share of patents in that class assigned to the industry and the total number of patents in that class in the YTC sample. For example, the table shows that 76 percent of patents in IPC classification C22B 21 are used by the aluminum industry. If there are 10 patents in this classification for a given year, 7.6 of them would be assigned to the aluminum industry. Finally, the energy patents used by each industry are utilized to construct the stock of energy knowledge, as represented by equation (4). The rates of decay and diffusion, $\beta_{1}$ and $\beta_{2}$, are parameters to be estimated by the model. Following the same steps, a stock of other knowledge, using non-energy related patents, 
is created as well.

\section{B. $R \& D$ Expenditure Data}

The next data needed are expenditures on $R \& D$ by industry. These data will be used to calculate benefit-cost ratios for energy $R \& D$. $R \& D$ expenditure data are available from the National Science Foundation ${ }^{8}$. Unfortunately, the data are not available at the level of detail used in this paper. Rather, they are presented at the 2-digit SIC level. To get the level of detail needed for this paper, the Yale Technology Concordance is used again.

The first step in constructing the $R \& D$ data is to find the total number of patents manufactured by industries at the two-digit SIC level. This corresponds to the level of data published by the NSF. The concordance of industry of manufacture is used in this step, because industry of manufacture is more likely to be related to R\&D expenditures than industry of use. Next, I find the number of patents manufactured by the industries in the dataset. Given this, I can calculate the percentage of patents manufactured by the two-digit industry that were manufactured by industries in the dataset. I multiply the R\&D data supplied by the NSF by this percentage to get $\mathrm{R} \& \mathrm{D}$ expenditures for the industry groups used in this paper.

\section{Manufacturing Data - The NBER Manufacturing Productivity Database}

Industry data for this study were taken from the NBER Manufacturing Productivity Database, which is available on-line from the NBER website. It is described in detail in Bartelsman and Gray (1994). The dataset provides annual information on 450 manufacturing industries from 1958 to 1991 . The data are presented at the 4-digit SIC level. Most of the data come from the Annual Survey of Manufactures (ASM) by the U.S. Census Bureau. For this paper, data on labor, capital, energy, and materials are needed, as well as prices for each. In this

\footnotetext{
${ }^{8}$ R\&D data are published in Research and Development in Industry, and are also available on-line.
} 
section, the variables used are described in detail.

The NBER dataset provides expenditures on each of the inputs used. For labor, the total payroll and the number of hours worked by production workers are provided. Wages are calculated as total spending on production workers divided by the number of production worker hours. Total payroll is deflated by the consumer price index to put it in real dollars.

For capital, the ASM survey provides investment information, but does not provide the value of the capital stock. The value of the capital stock is calculated in the NBER dataset by using the investment data, price deflators for 28 types of capital, and an investment flow matrix to determine the amount of investment in each type of capital for each industry. For the cost of capital, a price deflator for new investment, constructed by NBER, is used. The deflator takes into account the various compositions of capital stocks by industry.

Total expenditures on energy and materials are provided in the NBER dataset. In addition, price deflators for energy and materials are provided. The deflators are created by averaging together price deflators for the inputs used by each industry, ${ }^{9}$ and take into account changes in the mix of inputs used over time. Thus, each industry's price deflators for energy and material account for trends in the prices of inputs used in that industry.

\section{The Effect of New Patents on Industrial Energy Consumption}

Using the data described in section III, the variable factor demand equations can be estimated, and the effect of new patents on energy consumption can be calculated. Before proceeding, I first take a general look at the data. For each industry group, figure 2 presents a time series for energy prices (dashed line) and for energy intensity (solid line), with energy intensity defined as energy use divided by total output. Values in 1982 are normalized to 100. In

\footnotetext{
${ }^{9}$ Price indices for 369 materials and 6 types of energy are used. The six types of energy are electricity, residual fuel oil, distillates, coal, coke, and natural gas.
} 
most of the industry groups, energy intensity has been falling. The exceptions are aluminum and metal coating, although energy intensity does fall in the aluminum industry at the end of the sample. In addition, note that for most industries, energy intensity continues to fall even after energy prices level off, suggesting that technological change, in addition to simple factor substitution, plays a role in reducing energy intensity. Such a trend is particularly noticeable in industries such as chemicals, copper, and plastic film \& sheets.

The data are used to estimate the variable factor demand equations, (14), (15), and (16). To construct the stocks of knowledge, define the decay rate as $\beta_{1}=\frac{v}{1-v}$, and the rate of diffusion as $\beta_{2}=\frac{\lambda}{1-\lambda}$, where $0<v<1$ and $0<\lambda<1$. Estimation is carried out by searching over the range of $v$ and $\lambda$ for the rates of decay and diffusion that best fit the data. Given $\beta_{1}$ and $\beta_{2}$, the resulting variable factor demand equations are linear in parameters.

In theory, separate knowledge stocks can be constructed for knowledge pertaining to energy use and other technological advances. However, the results of such regressions are problematic. The advantage of using patent data for the energy knowledge stock is that we know the patents are related to saving energy. However, we do not know that the other patents are costsaving patents. Thus, the same problems that arise with using $R \& D$ expenditure data as an input arise, as discussed in section $\mathrm{I}^{10}$ As a result, a time trend is used for the stock of other knowledge. The equations to be estimated are:

\footnotetext{
${ }^{10}$ Estimations using patents to create the stock of other knowledge were done, but the results were not satisfactory. In particular, several of the estimated price elasticities were positive when patents were used to construct the stock of other knowledge. This occurs because of the problem of output being undervalued, since the patents used to create the stock of other knowledge may be product patents leading to unmeasured quality improvements in the industry's output.
} 
(18a)

$$
\begin{aligned}
\frac{E_{t}}{Y_{t}} & =\alpha_{E}+\alpha_{E E} \hat{p}_{E, t}+\alpha_{E M} \hat{p}_{M, t}+\alpha_{E C} \frac{C_{t-1}}{Y_{t}}+\phi_{E \dot{C}} \frac{\dot{C}_{t}}{Y_{t}}+ \\
& \alpha_{E K_{E}} \frac{K_{E, t-1}}{Y_{t}}+\alpha_{E K_{O}} t+\varepsilon_{E, t}
\end{aligned}
$$

$$
\begin{aligned}
\frac{M_{t}}{Y_{t}} & =\alpha_{M}+\alpha_{E M} \hat{p}_{E, t}+\alpha_{M M} \hat{p}_{M, t}+\alpha_{M C} \frac{C_{t-1}}{Y_{t}}+\phi_{M \dot{C}} \frac{\dot{C}_{t}}{Y_{t}}+ \\
& \alpha_{M K_{E}} \frac{K_{E, t-1}}{Y_{t}}+\alpha_{M K_{O}} t+\varepsilon_{M, t}
\end{aligned}
$$$$
\frac{L_{t}}{Y_{y}}=\alpha_{0}-\frac{1}{2}\left(\alpha_{E E} \hat{p}_{E, t}^{2}+2 \alpha_{E M} \hat{p}_{E, t} \hat{p}_{M, t}+\alpha_{M M} \hat{p}_{M, t}^{2}\right)+
$$$$
\alpha_{C} \frac{C_{t-1}}{Y_{t}}+\frac{\alpha_{C C}}{2} \frac{C_{t-1}^{2}}{Y_{t}^{2}}+\phi_{\dot{C}} \frac{\dot{C}_{t}}{Y_{t}}+\frac{\phi_{\dot{C} \dot{C}}}{2} \frac{\dot{C}_{t}^{2}}{Y_{t}^{2}}+\gamma_{C C} \frac{C_{t-1} \dot{C}_{t}}{Y^{2}}+
$$$$
\alpha_{K_{E}} \frac{K_{E, t-1}}{Y_{t}}+\frac{\alpha_{K_{E} K_{E}}}{2} \frac{K_{E, t-1}^{2}}{Y_{t}^{2}}+\frac{\alpha_{C K_{E}}}{2} \frac{C_{t-1} K_{E, t-1}}{Y_{t}^{2}}+\frac{\gamma_{C K_{E}}}{2} \frac{\dot{C}_{t} K_{E, t-1}}{Y_{t}^{2}}+\frac{\phi_{\dot{K}_{E} \dot{K}_{E}}}{2} \frac{\dot{K}_{E, t}^{2}}{Y_{t}^{2}}+
$$$$
\alpha_{K_{O}} t+\frac{\alpha_{K_{O} K_{O}}}{2} t^{2}+\frac{\alpha_{C K_{O}}}{2} \frac{C_{t-1} t}{Y_{t}}+\frac{\alpha_{K_{E} K_{O}}}{2} \frac{K_{E, t-1} t}{Y_{t}}+\frac{\gamma_{C K_{O}}}{2} \frac{\dot{C}_{t} t}{Y_{t}}+\varepsilon_{L, t}
$$

Using three staged least squares, a separate set of equations is estimated for each industry

group. The results are corrected for first-order autocorrelation. ${ }^{11}$ Data from 1959-1991 are used.

Because changes in the capital stock are correlated with prices, the price of investment was used

as an instrument. In addition, because of the effect of prices on the energy knowledge stock,

lagged prices of energy, $R \& D$, material, and investment were used as instruments for the stock of

energy knowledge. ${ }^{12}$ Maximum likelihood estimates of $\beta_{1}$ and $\beta_{2}$ are found by finding the

\footnotetext{
${ }^{11}$ One possible concern in using patent data is the variation in the quality of patents over time. Because the value of patents has tended to fall over time [see, for example, Popp 1998b, Griliches (1989), and Caballero and Jaffe (1993)], correcting the data for autocorrelation should account for much of the error caused by variations in patent quality. In an earlier version of this paper, additional regressions were run using patent counts weighted by quality, where the ratio of successful patents to R\&D was used as an indicator of the quality of research. This adjustment was found to have little effect on the results. Since the data used for the weights are only available since 1957, it is not possible to construct a reasonable stock of knowledge from the patent data until the mid-1960's. Thus, estimating the labor equation is not possible using the weighted patent counts. As a result, only the unweighted results are presented here.

${ }^{12}$ If an instrument for the lagged stock of knowledge is not used, many of the resulting price elasticities are positive.
} 
combination of $v$ and $\lambda$ that minimizes $0.5 \log |\hat{\Sigma}|$, where

$$
\hat{\Sigma}_{m n}=\frac{1}{T} \sum_{t=1}^{T} \hat{\varepsilon}_{t m} \hat{\varepsilon}_{t n}, \quad t=1,2, \ldots, T .
$$

Complete parameter estimates are presented in table $1 \mathrm{~A}$ of the appendix. The main results are summarized here. In general, the fit of the regressions seems good. Most parameters are significant, with the exception of the squared terms that are included only in the labor equation. Of particular interest is the parameter $\alpha_{E K E}$, which captures the effect of energy knowledge on energy consumption. This parameter is significant at the $95 \%$ level in nine of the thirteen equations.

Table 4 presents the estimated elasticities from this regression. Elasticities with respect to price are presented for energy and materials. All elasticities are calculated using the mean values for input levels and prices. In general, the estimated elasticities seem reasonable, although they are somewhat smaller than those found in similar studies. ${ }^{13}$ The mean value of the price elasticity of energy is -0.247 , and for materials is -0.077 . The smaller magnitude of the elasticities is likely due to the inclusion of the technology variables in the regression. These estimates include only changes in energy or materials consumption due to factor substitution. Changes due to new technologies are captured by the energy knowledge coefficients and the time trend.

For a first look at effect of technology on energy consumption, table 4 also shows the elasticity of energy consumption with respect to energy patents. A short run and a long run elasticity are given. The short run elasticity is the immediate effect of new patents on energy consumption. The long run elasticity uses the present value of energy savings until the knowledge embodied in the patents becomes obsolete. These are calculated as follows:

\footnotetext{
${ }^{13}$ See, for example, Berndt and Wood (1975), Griffin and Gregory (1976), or the papers in Berndt and Field (1982).
} 


$$
\begin{aligned}
S R \varepsilon_{E, P A T} & =\left(\frac{\partial E_{t}}{\partial K_{t-1}} \frac{\partial K_{t-1}}{\partial P A T_{t-1}}\right) \frac{\overline{P A} \bar{T}}{\bar{E}}=\alpha_{E K_{E}}\left(1-e^{-\beta_{2}}\right) \frac{\overline{P A} \bar{T}}{\bar{E}} \\
L R \varepsilon_{E, P A T} & =\left\{\sum_{t=0}^{\infty} e^{-\rho t}\left(\frac{\partial E_{t}}{\partial K_{t-1}} \frac{\partial K_{t-1}}{\partial P A T_{0}}\right)\right\} \frac{\overline{P A} \bar{T}}{\bar{E}} \\
& =\left\{\sum_{t=0}^{\infty} e^{-\rho t}\left(\alpha_{E K_{E}} e^{-\beta_{1}(t-1)}\left(1-e^{-\beta_{2} t}\right)\right)\right\} \frac{\overline{P A} \bar{T}}{\bar{E}}
\end{aligned}
$$

A discount rate of 0.07 was used for the long-run calculations. This rate is equal to the mean of the preferred dividend rate for medium-risk companies, and is often used in studies such as this (see, for example, Epstein and Denny (1983) and Bernstein and Nadiri (1989)). The results are not very sensitive to other values of the discount rate.

Overall, the results suggest that new technologies do have an important effect on energy consumption. The mean long-run elasticity of energy consumption with respect to patents is -0.195. In most industries, the elasticity of energy consumption with respect to new patents is slightly smaller than the price elasticity of energy consumption. The elasticities of energy with respect to new energy patents are negative for nine of the thirteen industries. The four exceptions are aluminum, glass, metal coating, and rolling and casting. Looking back at figure 2, we see that these results could have been expected. In these industries, energy intensity and energy prices seem to be strongly correlated. This suggests that technological change did not play a crucial role in these industries.

To see the full impact of energy $\mathrm{R} \& \mathrm{D}$, table 5 presents the amount of energy saved in each industry due to a new energy patent. ${ }^{14}$ The average energy savings are substantial. In the short run, the average savings are 2 million dollars. The average of the nine groups with actual savings is 3.2 million dollars. In the long run, the average savings are 20.3 million dollars, and

\footnotetext{
${ }^{14}$ The calculations are the portions of equations (19) and (20) contained in brackets.
} 
rise to 34.0 million dollars if only the groups that experience savings are included. To put these numbers in perspective, an average of 2.25 million dollars of R\&D was spent per patent in these 13 industries.

In addition, a benefit to cost ratio and a rate of return are presented, using the R\&D cost data as described in section III. The rates of return on these investments are quite high. The mean rate of return is 0.98 . In only one of the industries experiencing positive savings, automotives, is the rate of return less than 0.10 . It may be the case that, in the auto industry, the energy patents are product, rather than process, patents. For example, combustion patents in the automotive industry may relate to improvements in automobile engines, as opposed to improvements in combustion processes related to the manufacture of automobiles.

Although the rates of return on these investments are quite high, note that these are social rates of return, as they capture the industry-wide savings resulting from a new patent. A single firm investing in $R \& D$ will not take the gains of other firms into account. Thus, we would expect underinvestment. In particular, there is a correlation between total energy usage in an industry and the rate of return. The rates of return are highest in industries with the greatest energy use. Presumably the potential industry-wide gains from research were highest here. ${ }^{15}$

In addition, the social rates of return discussed so far only include the benefits of energy conservation. It is possible, however, that new energy technologies could affect the use of other inputs as well. As such, the right hand side of table five presents total variable cost savings resulting from a new energy patent. The mean and median rate of returns are somewhat larger than when only energy use is considered, although the energy savings do provide the greatest

\footnotetext{
${ }^{15}$ More research is necessary here. Since we are concerned with spillovers, what we really need to know is whether there are more firms in the industries with the highest social rates of returns. In these cases, the likelihood of positive spillovers would be greatest.
} 
benefit to this research. In fact, in four of the industries, the total savings are significantly less than the energy savings, suggesting that the new technologies required more labor or materials than did earlier technologies. ${ }^{16}$

Finally, table 6 presents the estimated rates of decay and diffusion. The mean decay rate is 0.31 , and the mean rate of diffusion is 0.33 . However, in each case, the mean values are driven by a few outliers, as the median values are much lower. The median rate of decay is 0.22 , and the median diffusion is 0.03 . Industries with low rates of decay and diffusion, such as copper and steel foundries, are established industries that do not have a reputation for much technological innovation. If new knowledge is not produced or disseminated quickly, it will not become obsolete quickly. Industries that are known for greater innovation, such as chemicals, have higher rates of decay and diffusion.

Given the rates of decay and diffusion, we can find the effect that a new patent has on the stock of knowledge for each year after its initial application. Recall from equation (4) that the weight a patent applied for $s$ years earlier has on the stock of knowledge today is equal to $e^{-\beta_{1} s}\left(1-e^{-\beta_{2}(s+1)}\right)$. Figure 3 presents this weight for the first 50 years of a new patent's life. Note that, for most industries, three to five years pass before a new patent has its biggest impact. After this, the effect of decay dominates the effect of diffusion, and the influence of the patent declines.

The number of years that pass before a new patent has its greatest effect on the stock of knowledge is presented in table 6 . These figures can be seen as the peaks of the graphs in table 3 . The mean is 9.77 years, and the median is three years. In addition, the year of maximum weight

\footnotetext{
${ }^{16}$ Keep in mind that the total variable cost savings do not account for changes in the capital stock required by new technologies. There are not enough observations available in the data set to estimate all of the parameters needed for such a calculation.
} 
for the mean and median values of the rates of decay and diffusion is also found. For the mean values, a patent has its maximum influence after just one year. The year of maximum influence calculated by using the median rates of decay and diffusion is three years. This result is consistent with the notion that the process of disseminating new knowledge, along with adjustment costs necessary to install new equipment, delay the benefits of new research.

\section{The Impact of a Ten Percent Energy Tax}

Section IV calculates the effect that a single new energy patent has on energy consumption. However, to truly understand the influence that technologies induced from environmental policy have on energy consumption, it is necessary to consider the effect that policy has on innovation. This section brings together the results of section IV and the results on induced innovation from Popp (1998a,b) to determine the impact of a price increase on energy consumption. It distinguishes between induced innovation - new technologies that were developed in response to changes in the price of energy - and factor substitution - a movement along a production isoquant, holding technology constant. A dynamic simulation of the imposition of a ten percent energy tax is used to illustrate the results. The major finding is that, although factor substitution is dominant immediately after the imposition of a tax, the cumulative effect of research causes induced innovation to play a much greater role than factor substitution in the reduction of industrial energy consumption in the long run.

Table 7 identifies the effects of factor substitution and induced innovation on short run energy consumption in the eight industries from section IV for which patents contributed significant energy savings: chemicals, copper, electrometallurgical, iron foundries, plastic film \& sheet, pulp \& paper, steel foundries, and steel pipes \& tubes. The effect is for patents developed a year after the price increase, so as to allow time for lagged reactions to the price change. 
The first column of the table presents the elasticity of energy patents with respect to a change in energy prices. This figure was calculated in Popp (1998a). ${ }^{17}$ The elasticity of energy use with respect to patents, as calculated in section IV, is presented next. The elasticity of energy use with respect to induced innovation is the product of these two elasticities. It is the percent change in energy consumption resulting from the new technologies induced by a one percent change in energy prices. Formally, the relationship is:

$\Delta \mathrm{E}$ due to induced technological change $=f[$ patents(price $)]$.

Continuing with table 7 , the fourth column presents the elasticity of energy use with respect to price, also calculated in section IV. This is the change in energy consumption resulting from factor substitution. Column 5 shows the total effect of a change in energy prices. It is the sum of the elasticities with respect to induced innovation and factor substitution found in columns three and four. Finally, column 6 shows the percentage of the total elasticity which is due to induced innovation.

The total elasticity of energy consumption ranges from -0.085 for steel pipes \& tubes to -1.158 for chemicals. Note that by combining the effects of induced innovation and factor substitution, the elasticities calculated are similar to those found in other work. The short-run elasticity for factor substitution is greater than the induced innovation elasticity for all industries except iron and plastic. In the other six industries, induced innovation accounts for between 2 and 10 percent of the total change in energy consumption in the short run.

\footnotetext{
${ }^{17}$ Popp (1998a) provides results for several different energy technologies. The elasticity for the most important technology for each industry is used in table 7. For industries that are not represented by a specific technology in Popp (1998a), a pooled estimate from all industrial technologies is used. The technologies used for each industry are: electrolytic production of metals (copper, electrometallurgical, plastic film \& sheets), continuous casting (steel and iron foundries), and the pooled results (chemicals, pulp \& paper, and steel pipes \& tubes).
} 


\section{A. Dynamics}

The results in table 7 only present the savings that result from new technology developed in the year immediately after the energy tax is imposed. However, as long as the tax remains in effect, energy prices will remain higher, and incentives for additional energy R\&D will exist. Thus, the energy savings from induced technological change will not only include innovations developed in the year of the tax, but also innovations developed in subsequent years. In addition, because it takes time for new inventions to diffuse through society, even a patent developed right after the tax is imposed will not have its full effect for a few years. As such, induced innovation should play a more important role in the long run.

In this section, a simple dynamic simulation is carried out to assess the long-term impact of induced innovation. The simulation examines the effect of an energy tax that raises energy prices by ten percent. To calculate the long-run effects of the tax, it is necessary to consider how the productivity of R\&D varies over time. Estimates on the productivity of research from Popp (1998b) are used to account for changes in the returns to R\&D over time. That paper showed that the returns to energy research fall over time. As a result, the number of new patents created will fall over time as well. It should be noted, however, that the simulation presented here is far from complete. It assumes no changes in factor prices over time. A more complete, general equilibrium modeling effort would allow the pre-tax price of energy to fall as the demand curve for energy shifted inwards, and would account for price changes in other factors as well. It is hoped that the results of this paper will help modelers of energy incorporate induced innovation into their models.

Figure 4 plots the number of patents induced by a ten percent energy tax. The calculations are similar to those in table 7, except that both price and technological opportunity are used to determine the number of patents developed in a given year. For copper, 
electrometallurgical, iron, plastic, and steel, productivity estimates obtained in Popp (1998a,b) are used to measure technological opportunity. These estimates vary over time, as both the passage of time and increased innovation have a negative effect on the productivity parameter estimates, as shown in Popp (1998b). The relationship is:

$$
\text { patents }_{t}=f\left[\text { price, } \text { productivity }\left(\text { time, }_{\text {patents }} \text { pr-1 }\right)\right] \text {. }
$$

For the remaining industries, technological opportunity is measured by a time trend. The relationship is:

$$
\text { patents }_{t}=f(\text { price, } \text { time }) \text {. }
$$

The elasticities of patenting activity with respect to either the productivity estimates or with respect to time are found in Popp (1998a). ${ }^{18}$

The shape of the time paths in figure four depends on the rates of decay and diffusion calculated in section IV, and is also influenced by diminishing returns to research. Diminishing returns to research lessen the induced innovation effect in later years. Even though energy prices remain high, firms will be less likely to invest in new R\&D if the likelihood of successful research has fallen. The rates of decay and diffusion affect the usefulness of early patents induced by the price change. Rapid decay and diffusion implies that the usefulness of early patents induced by the price change is declining. As a result, in industries that patents achieve their peak usefulness quickly, such as chemicals, the knowledge stocks flatten out. In industries that experience technological change more slowly, such as steel, the knowledge stocks continue to grow.

Having calculated the change to the stock of knowledge in each year after the energy tax

\footnotetext{
18 The elasticity of energy patents with respect to time is: 0.054 (chemicals, pulp \& paper, and steel pipes \& tubes). The elasticities with respect to productivity estimates are 0.266 (copper, electrometallurgical, and plastic film \& sheets), and 0.061 (iron and steel foundries). Note that the productivity estimates decline over time, so that a positive elasticity with respect to the productivity estimates implies diminishing returns to research.
} 
is imposed, the total energy savings due to induced innovation can now be found by multiplying the size of the stock of knowledge times the effect that a single patent has on energy consumption. Figure five illustrates the results. The figure shows energy savings due to induced technological change for the first 20 years after an energy tax is imposed. The solid line represents energy savings due to induced innovation, and the dashed line presents savings due to factor substitution. ${ }^{19}$ The initial impact of induced technological change is smaller than the impact of factor substitution for all the technology groups. However, as time passes, higher prices maintain the incentives for developing new technology, so that the stock of knowledge induced by the price change grows. Soon, savings from induced technological change dominate savings from factor substitution. In most of the industries, the effect of induced innovation overtakes factor substitution between five and ten years after the imposition of the energy tax. As with the time paths for the stock of knowledge, the shapes of the induced innovation time paths are influenced by the rates of decay and diffusion of knowledge in each industry. However, note that the chemical industry is the only industry in which the effect of induced innovation levels off before overtaking the effect of factor substitution.

\section{Conclusions}

This paper has combined patent data and industry-level input and price data to estimate the effect of new energy patents on energy consumption in thirteen industry groups. The median present value of long run energy savings in the nine groups experiencing savings is nearly 9 million dollars. This suggests a rate of return of 0.63 . The median rate of decay for a new patent is 0.22 , and the average rate of diffusion is 0.03 , indicating that a patent has its largest effect on energy consumption three years after the initial patent application.

\footnotetext{
${ }^{19}$ Since the estimated price elasticity of energy consumption is positive for the iron industry, there is no line for factor substitution on that figure.
} 
The evidence presented in this paper suggests that induced technological change will play an important role in reducing energy consumption after a price increase. In particular, although the direct impact of factor substitution is more important than induced innovation in the short run, the savings from induced innovation are more important over the long run. The long run significance of induced innovation occurs because the elasticities of patents with respect to energy prices tend to be greater than one, and because of the cumulative effects of research on the knowledge stock. When designing environmental policies, lawmakers should take these results into account, and design policies that encourage innovation. As prices are more likely to induce a continuously high level of innovation than standards, this result provides another argument in favor of market-based environmental policies. 


\section{REFERENCES}

Bartelsman, Eric and Wayne Gray (1994), "NBER Manufacturing Productivity Database," NBER Technical Working Paper, available on-line.

Berndt, Ernst (1990), "Energy Use, Technical Progress and Productivity Growth: A Survey of Economic Issues," The Journal of Productivity Analysis, 2, 67-83.

Berndt, Ernst and Barry Field, eds. (1982), Modeling and Measuring Natural Resource Substitution, MIT Press, Cambridge, MA.

Berndt, Ernst, Charles Kolstad, and Jong-Kun Lee (1993), "Measuring the Energy Efficiency and Productivity Impacts of Embodied Technical Change," The Energy Journal, 14, 33-55.

Berndt, Ernst, Catherine Morrison, and G. Campbell Watkins (1981), "Dynamic Models of Energy Demand: An Assessment and Comparison," in Modeling and Measuring Natural Resource Substitution, Ernst Berndt and Barry Field eds., MIT Press, Cambridge, MA.

Berndt, Ernst and David Wood (1975), "Technology, Prices, and the Derived Demand for Energy," Review of Economics and Statistics, 57, 376-384.

Bernstein, Jeffrey I. and M. Ishaq Nadiri (1989), "Research and Development and Intra-industry Spillovers: An Empirical Application of Dynamic Duality," Review of Economic Studies, $56,249-269$.

Caballero, Ricardo J. and Adam B. Jaffe (1993), "How High are the Giants' Shoulders: An Empirical Assessment of Knowledge Spillovers and Creative Destruction in a Model of Economic Growth," in Olivier J. Blanchard and Stanley Fischer, eds., NBER Macroeconomics Annual 1993, MIT Press, Cambridge, MA.

Cuneo, Philippe and Jacques Mairesse (1984), "Productivity and R\&D at the Firm Level in French Manufacturing," in $R \& D$, Patents, and Productivity, Zvi Griliches, ed., University of Chicago Press, Chicago, IL, 375-392.

Epstein, Larry G. and Michael G.S. Denny (1983), "The Multivariate Flexible Accelerator Model: Its Empirical Restrictions and an Application to U.S. Manufacturing," Econometrica, 51, 647-673.

Evenson, Robert E., Jonathan Putnam, and Samuel Kortum (1991), "Estimating Patent Counts by Industry Using the Yale-Canada Concordance," final report to the National Science Foundation.

Griffin, J.M. and P.R. Gregory (1976), "An Intercountry Translog Model of Energy Substitution Responses," American Economic Review, 66, 545-857.

Griliches, Zvi (1995), "R\&D and Productivity: Econometric Results and Measurement Issues," in Handbook of the Economics of Innovation and Technological Change, Paul Stoneman ed., Blackwell Publishers, Cambridge, MA, 52-89. 
Griliches, Zvi (1990), "Patent statistics as economic indicators," Journal of Economic Literature, 28, 1661-1707.

Griliches, Zvi (1989), "Patents: Recent trends and puzzles," Brookings Papers on Economic Activity: Microeconomics, 291-330.

Griliches, Zvi and Jacques Mairesse (1984), "Productivity and R\&D at the Firm Level," in $R \& D$, Patents, and Productivity, Zvi Griliches, ed., University of Chicago Press, Chicago, IL, 339-374.

Jorgenson, Dale W. and Barbara M. Fraumeni (1981), "Relative Prices on Technical Change," in Modeling and Measuring Natural Resource Substitution, Ernst R. Berndt \& Barry C. Field eds., MIT Press, Cambridge, MA, 17-47.

Kortum, Samuel and Jonathan Putnam (1989), "Estimating Patents by Industry: part I and II," unpublished.

Kortum, Samuel and Jonathan Putnam (1997), “Assigning Patents by Industry: Tests of the Yale Technology Concordance,” Economic Systems Research, 9, pp. 161-175.

Mountain, Dean C., Bill P. Stipdonk, and Cathy J. Warren (1989), “Technological Innovation and a Changing Energy Mix -- A Parametric and Flexible Approach to Modeling Ontario Manufacturing," The Energy Journal, 10, 139-158.

Popp, David (1998a), "Induced Innovation and Energy Prices," working paper, The University of Kansas.

Popp, David (1998b), “The Productivity of Energy Research,” working paper, The University of Kansas.

Scherer, Frank (1993), "Lagging productivity growth: measurement, technology and shock effects," Empirica, 20, 5-24.

Sterner, Thomas (1990), "Energy Efficiency and Capital Embodied Technical Change: The Case of Mexican Cement Manufacturing," The Energy Journal, 11, 155-167.

Trajtenberg, Manuel (1990), “A Penny for Your Quotes: Patent Citations and the Value of Innovations," RAND Journal of Economics, 21, 172-187.

Treadway, A.B. (1974), "The Globally Optimal Flexible Accelerator," Journal of Economic Theory, 7, 7-39.

Watkins, G. Campbell and Ernst Berndt (1992), "Dynamic Models of Input Demands: A Comparison Under Different Formulations of Adjustment Costs," in Advances in the Economics of Energy and Resources, vol. 7, John R. Moroney ed., JAI Press, Greenwich, CT. 


\section{Table 1: International Patent Classifications Used in Factor Demand Function Analysis}

\section{Industrial Technologies}

Waste heat:

F01K 17

F01K 19

F01K 23

F02G

Steam engine plants; Steam accumulators; Engine plants not otherwise provided for; Engines using special working fluids or cycles/Use of steam or condensate extracted or exhausted from steam engine plant Steam engine plants; Steam accumulators; Engine plants not otherwise provided for; Engines using special working fluids or cycles/Regenerating or otherwise treating steam exhaust from steam engine plant Steam engine plants; Steam accumulators; Engine plants not otherwise provided for; Engines using special working fluids or cycles/Plants characterized by more than one engine delivering power to the plant, the engines being driven by different fluids

Hot gas or combustion product positive-displacement engine plants; Use of waste heat of combustion engines, not otherwise provided for

Heat Pumps:

F25B 13

F25B 29

Refrigeration machines, plants or systems; Combined heating and refrigeration systems, e.g. heat pump systems/Compression refrigeration machines, plants, or systems, with reversible cycle, e.g. for use as heat pumps

Refrigeration machines, plants or systems; Combined heating and refrigeration systems, e.g. heat pump systems/Combined heating and refrigeration systems, e.g. heat-pump systems

Heat exchange: F28

Heat exchange in general

Continuous casting: B22D 11

Casting of metals; Casting of other substances by the same processes or devices/Continuous casting of metals, i.e. casting in indefinite lengths 
Table 1: International Patent Classifications Used in Factor Demand Function Analysis

\author{
Metallurgical processes: \\ C21D \\ Modifying the physical structure of ferrous metals; General devices for \\ heat treatment of ferrous or non-ferrous metals or alloys; Making metal \\ malleable by decarburisation, tempering, or other treatments \\ C22B 4 \\ Production or refining of metals; Pretreatment of raw \\ materials/Electrothermal treatment of ores or metallurgical products for \\ obtaining metals or alloys \\ $\mathrm{C} 23 \mathrm{C}$ \\ Coating metallic material; Coating material with metallic material; Surface \\ treatment of metallic material by diffusion into the surface, by chemical \\ conversion or substitution; Coating by vacuum evaporation, by sputtering, \\ by ion implantation or by chemical vapour deposition, in general \\ $\mathrm{C} 25 \mathrm{C}$ \\ Processes for the electrolytic production, recovery or refining of metals; \\ Apparatus therefor \\ C25D Processes for the electrolytic or electrophoretic production of coatings; \\ electroforming; apparatus therefor
}

Production of aluminum:

C22B 21

Production or refining of metals; Pretreatment of raw materials/Obtaining aluminum

Paper production: D21C 11

Production of cellulose by removing non-cellulose substances from cellulose-containing materials; Regeneration of pulping liquors; Apparatus therefor/Regeneration of pulp liquors

Combustion:

F02

F02B 19

F23

F23L 7

Combustion engines; Hot-gas or combustion-product engine plants Internal-combustion piston engines; Combustion engines in general/Engines with precombustion chambers Combustion apparatus; Combustion processes Air supply; Draught-inducing; supplying non-combustible liquid or gas/Supplying non-combustible liquid or gases, other than air, to the fire, e.g. oxygen, steam

F23L 15

Air supply; Draught-inducing; supplying non-combustible liquid or gas/Heating of air supplied for combustion

F23N 5 Regulating or controlling combustion/Systems for controlling combustion 
Table 1: International Patent Classifications Used in Factor Demand Function Analysis

\author{
Supply Technologies \\ Using waste as fuel: \\ F23G 5
}

F23G 7

Solar Energy:

F03G 7

F24J 2

H01L 25

H01L 31

H01L 35

H01L 37

H02N 6
Cremation furnaces; Consuming waste by combustion/Incineration of waste; Incinerator constructions; Details, accessories or control therefor Cremation furnaces; Consuming waste by combustion/Incinerators or other apparatus for consuming industrial waste, e.g. chemicals

Spring, weight, inertial, or like motors; Mechanical-power-producing devices or mechanisms, not otherwise provided for or using energy sources not otherwise provided for/ Mechanical-power-producing devices or mechanisms, not otherwise provided for or using energy sources not otherwise provided for

Production or use of heat not otherwise provided for/Use of solar heat, e.g. solar collectors

Semiconductor devices; Electric solid state devices not otherwise provided for/Assemblies consisting of a plurality of individual semiconductor or other solid state devices, e.g. solar panels

Semiconductor devices; Electric solid state devices not otherwise provided for/Semiconductor devices sensitive to infra-red radiation, light, electromagnetic radiation of shorter wavelength, or corpuscular radiation and adapted for the conversion of the energy of such radiation into electrical energy or for the control of electrical energy by such radiation; Processes or apparatus peculiar to the manufacture or treatment thereof or parts thereof; Details thereof

Semiconductor devices; Electric solid state devices not otherwise provided for/Thermelectric devices comprising a junction of dissimilar materials, i.e. exhibiting a Seebeck or Peltier effect with or without other thermoelectric effects or thermomagnetic effects; Processes or apparatus peculiar to the manufacture or treatment thereof or of parts thereof; Details thereof

Semiconductor devices; Electric solid state devices not otherwise provided for/Thermelectric devices without a junction of dissimilar materials; Thermomagnetic devices, eg. using Nernst-Ettinghausen effect; Processes or apparatus peculiar to the manufacture or treatment thereof or of parts thereof

Electric machines not otherwise provided for/Generators in which light radiation is directly converted into electrical energy 


\section{Table 1: International Patent Classifications Used in Factor Demand Function Analysis}

Wind power:

F03D

Coal gasification: C10J 3

C10K 3

Coal liquefaction: C10G 1

Fuel Cells:

H01M 8

\author{
Wind motors
}

Production of producer gas, water-gas, synthesis gas from solid carbonaceous material, or mixtures containing these gases; Carburetting air or other gases/Production of combustible gases containing carbon monoxide from solid carbonaceous fuels

Purifying or modifying the chemical compositions of combustible technical gases containing carbon monoxide/Modifying the chemical composition of combustible technical gases containing carbon monoxide to produce an improved fuel, e.g. one of different calorific value, which may be free of carbon monoxide

Cracking hydrocarbon oils; Production of liquid hydrocarbon mixtures from materials other than hydrocarbons, e.g. by destructive hydrogenation; Recovery of hydrocarbon oils from oil-shale, oil-sand, or gases; Refining mixtures mainly consisting of hydrocarbons; Reforming of naphtha; Mineral Waxes/Production of liquid hydrocarbon mixtures from oil shale, oil-sand, or non-melting solid carbonaceous or similar materials, e.g. wood, coal

Processes or means, e.g. batteries, for the direct conversion of chemical into electrical energy/Fuel cells; Manufacture thereof 


\section{Table 2: Concordance Between U.S. and Canadian Industry Codes}

\section{Canadian Industrial Classifications \\ Aluminum \\ 2951 Primary Production of Aluminum \\ Automotive \\ 3231 Motor Vehicle Industry \\ Chemicals \\ 3711 Industrial Inorganic Chemical Industries, nec \\ 3712 Industrial Organic Chemical Industries, nec \\ 3721 Chemical Fertilizers Industry \\ 3729 Other Agricultural Chemical Industries \\ 3799 Other Chemical Products Industries, nec}

Copper

2959 Other Non-Ferrous Smelting \& Refining

Electrometallurgical Products

2911 Ferro-Alloys Industry

Glass Industry

3561 Primary Glass \& Containers Industry

3562 Glass Products Exc. Containers Industry

Iron Foundries

2941 Iron Foundries

Metal Coating

3041 Custom Coating of Metal Products Industry

3921 Jewelry \& Silverware Industry

Plastic Film \& Sheet

1611 Foamed \& Expanded Plastic Products Industry

1621 Plastic Pipe \& Pipe Fittings Industry

1631 Plastic Film \& Sheeting Industry

1699 Other Plastic Products Industries, nec

3731 Plastic \& Synthetic Resin Industry

\section{U.S. Industrial Classifications}

3334

3771

2812

2813

2816

2819

2822

2842

2843

2861

2865

2869

2873

2874

2879

2892

2895

2899

3482

3483

3331

3332

3333

3339

3313

3229

3231

3321

3322

3471

3479

3911

3914

3915

3961

2821

3041

3079

3081

3082

3083

3085

3088
Primary Aluminum

Motor Vehicles and Car Bodies

Alkalies and Chlorine

Industrial Gases

Industrial Pigments

Industrial Inorganic Chemicals, nec

Synthetic Rubber

Polishes and Sanitation Goods

Surface Active Agents

Gum and Wood Chemicals

Cyclic Crudes and Intermediates

Industrial Organic Chemicals, nec

Nitrogenous Fertilizers

Phosphatic Fertilizers

Agricultural Chemicals, nec

Explosives

Carbon Black

Chemical Preparations, nec

Small Arms Ammunition

Ammunition, Exc. For Small Arms, nec

Primary Copper

Primary Lead

Primary Zinc

Primary Nonferrous Metals, nec

Electrometallurgical Products

Pressed and Blown Glass, nec

Products of Purchased Glass

Gray and Ductile Iron Foundries

Malleable Iron Foundries

Plating and Polishing

Metal Coating and Allied Services

Jewelry, Precious Metal

Silverware and Plated Ware

Jewelers' Materials \& Lapidary Work

Costume Jewelry

Plastic Materials and Resin

Rubber \& Plastics Hose \& Belting

Miscellaneous Plastic Products

Unsupported Plastics Film \& Sheet

Unsupported Plastics Profile Shapes

Laminated Plastics Plate \& Sheet

Plastics Bottles

Plastics Plumbing Fixtures 


\section{Canadian Industrial Classifications}

Pulp and Paper

2711 Pulp Industry

Rolling, Casting, and Extruding

2919 Other Primary Steel Industries

2961 Aluminum Rolling, Casting \& Extruding

2971 Copper Rolling, Casting \& Extruding

2999 Other Rolling, Casting \& Extruding

3052 Wire \& Wire Rope Industry

3059 Other Wire Products Industries

3381 Communications \& Energy Wire \& Cable

Steel Foundries

2912 Steel Foundries

Steel Pipes and Tubes

2921 Steel Pipe \& Tube Industry

\section{U.S. Industrial Classifications}

3089

Plastic Products, nec

2611

Pulp Mills

3361

3362

3369

3549

3623

3312

3316

3399

3315

3341

3351

3353

3354

3355

3356

3357

3399

3463

3496

3497

3324

3325

Aluminum Foundries

Brass, bronze, and copper foundries

Nonferrous foundries, nec

Metalworking machinery, nec

Welding apparatus, electric

Blast Furnaces and Steel Mills

Cold Finishing of Steel Shapes

Primary Metal Products, nec

Steel Wire and Related Products

Secondary Nonferrous Metals

Copper Rolling and Drawing

Aluminum Sheet, Plate, and Foil

Aluminum Extruded Products

Aluminum Rolling and Drawing, nec

Nonferrous Rolling and Drawing, nec

Nonferrous Wiredrawing \& Insulating

Primary Metal Products

Nonferrous Forgings

Miscellaneous Fabricated Wire Products

Metal Foil and Leaf

Steel Investment Foundries

Steel Foundries, nec

3317 Steel Pipe and Tubes 
Table 3: Major Energy Patent Classifications in Industry Groups

\begin{tabular}{|lrrr|}
\hline Industry Group & IPC Classification & $\begin{array}{r}\text { Patents Assigned to Industry } \\
\text { /Total Patents in Sample }\end{array}$ & Share \\
\hline Aluminum & C22B 21: producing aluminum & $36 / 47$ & 0.766 \\
& C25C: electrolytic apparatus & $126 / 387$ & 0.326 \\
\hline Automotive & C25D: electrolytic apparatus & $11 / 676$ & 0.016 \\
& F02: combustion & $741 / 2277$ & 0.325 \\
& F23: combustion & $23 / 1530$ & 0.015 \\
& F28: heat exchange & $55 / 745$ & 0.074 \\
\hline Chemical & C23C: coating metal & $58 / 1145$ & 0.051 \\
\hline Copper & C22B 4: electrothermal treatment & $14 / 24$ & 0.583 \\
& C25C: electrolytic apparatus & $118 / 387$ & 0.305 \\
\hline Electrometallurgical & C21D: treating metal & $4 / 526$ & 0.008 \\
& C22B 4: electrothermal treatment & $2 / 24$ & 0.083 \\
\hline Glass & C23C: coating metal & $31 / 1145$ & 0.027 \\
\hline Iron Foundries & B22D 11: continuous casting & $15 / 565$ & 0.002 \\
& C21D: treating metal & $7 / 526$ & 0.013 \\
\hline Metal Coating & C21D: treating metal & $12 / 526$ & 0.023 \\
& C23C: coating metal & $527 / 1145$ & 0.460 \\
& C25C: electrolytic apparatus & $11 / 387$ & 0.028 \\
& C25D: electrolytic apparatus & $428 / 676$ & 0.633 \\
\hline Plastic Film \& Sheet & C23C: coating metal & $53 / 1145$ & 0.046 \\
& C25D: electrolytic apparatus & $15 / 676$ & 0.022 \\
\hline Pulp \& Paper & D21C 11: black liquor: & $107 / 113$ & 0.947 \\
\hline Rolling \& Casting & B22D 11: continuous casting & $418 / 565$ & 0.740 \\
& C21D: treating metal & $255 / 526$ & 0.485 \\
& C23C: coating metal & $60 / 1145$ & 0.052 \\
& C25C: electrolytic apparatus & $14 / 387$ & 0.036 \\
& C22D : electrolytic apparatus & $28 / 676$ & 0.041 \\
\hline Steel Pipes \& continuous casting & $81 / 565$ & 0.143 \\
\hline & C21D: treating metal & $13 / 526$ & 0.002 \\
\hline
\end{tabular}


Table 4 -- Elasticities

\begin{tabular}{|c|c|c|c|c|}
\hline Industry Group & $\varepsilon_{\mathrm{M}, \mathrm{Pm}}$ & $\varepsilon_{\mathrm{E}, \mathrm{Pe}}$ & $S R \varepsilon_{E, P A T}$ & LR $\varepsilon_{\mathrm{E}, \mathrm{PAT}}$ \\
\hline Aluminum & -0.169 & -0.369 & 0.012 & 0.138 \\
\hline Automotive & -0.052 & 0.781 & -0.135 & -0.585 \\
\hline Chemicals & -0.181 & -1.140 & -0.055 & -0.683 \\
\hline Copper & -0.015 & -0.210 & -0.003 & -0.186 \\
\hline Electrometallurgical & -0.282 & -0.808 & -0.019 & -0.641 \\
\hline Glass & -0.159 & -0.218 & 0.016 & 0.504 \\
\hline Iron Foundries & 0.044 & 0.009 & -0.077 & -0.711 \\
\hline Metal Coating & -0.052 & -0.261 & 0.097 & 0.182 \\
\hline Plastic Film \& Sheet & 0.029 & -0.108 & -0.059 & -0.099 \\
\hline Pulp \& Paper & -0.178 & -0.355 & -0.042 & -0.171 \\
\hline Rolling \& Casting & 0.071 & -0.018 & 0.028 & 0.399 \\
\hline Steel Foundries & -0.094 & -0.430 & -0.002 & -0.254 \\
\hline Steel Pipes \& Tubes & 0.044 & -0.083 & -0.008 & -0.425 \\
\hline mean & -0.077 & -0.247 & -0.019 & -0.195 \\
\hline median & -0.052 & -0.218 & -0.008 & -0.186 \\
\hline
\end{tabular}

NOTE: Elasticities calculated using mean levels of inputs.

The table presents elasticities from both the unweighted and weighted patent regressions. The first three columns of each set of results are the price elasticities for labor, materials, and energy. Next is the short-run elasticity of energy with respect to patents, as defined in equation (19), and the long-run elasticity of energy with respect to patents, as defined in equation (20). The final row provides the mean and median values of the estimates. 
Table 5 -- Cost Savings From a New Energy Patent

millions of 1987 dollars

\begin{tabular}{|c|c|c|c|c|c|c|c|c|c|c|c|}
\hline \multirow[b]{3}{*}{ Industry Group } & \multirow[b]{3}{*}{$R \& D /$ patent } & \multicolumn{5}{|c|}{ Energy Savings } & \multicolumn{5}{|c|}{ Total Variable Cost Savings } \\
\hline & & \multicolumn{2}{|c|}{ short run } & \multicolumn{3}{|c|}{ long run } & \multicolumn{2}{|c|}{ short run } & \multicolumn{3}{|c|}{ long run } \\
\hline & & $\Delta$ energy & $\mathrm{B} / \mathrm{C}$ & $\Delta$ energy & $\mathrm{B} / \mathrm{C}$ & ror & $\Delta$ energy & $\mathrm{B} / \mathrm{C}$ & $\Delta$ energy & $\mathrm{B} / \mathrm{C}$ & ror \\
\hline Aluminum & 3.13 & 0.47 & -0.15 & 5.40 & -1.73 & -- & -0.91 & 0.29 & -10.48 & 3.35 & 0.547 \\
\hline Automotive & 4.61 & -0.27 & 0.06 & -1.16 & 0.25 & 0.001 & 0.35 & -0.08 & 1.53 & -0.33 & - \\
\hline Chemicals & 1.50 & -9.19 & 6.12 & -114.56 & 76.31 & 2.408 & -8.91 & 5.94 & -111.04 & 73.96 & 2.381 \\
\hline Copper & 2.35 & -0.06 & 0.02 & -3.69 & 1.57 & 0.131 & -0.12 & 0.05 & -7.66 & 3.26 & 0.213 \\
\hline Electrometallurgical & 2.54 & -1.84 & 0.72 & -60.83 & 23.96 & 0.936 & -0.14 & 0.06 & -4.78 & 1.88 & 0.194 \\
\hline Glass & 1.90 & 0.59 & -0.31 & 18.36 & -9.64 & -- & -2.26 & 1.19 & -70.09 & 36.81 & 1.304 \\
\hline Iron Foundries & 3.02 & -10.60 & 3.51 & -98.00 & 32.47 & 1.992 & 10.41 & -3.45 & 96.30 & -31.91 & -- \\
\hline Metal Coating & 0.34 & 0.11 & -0.32 & 0.20 & -0.60 & -- & 0.80 & -2.36 & 1.50 & -4.42 & -- \\
\hline Plastic Film \& Sheet & 0.92 & -5.30 & 5.75 & -8.99 & 9.75 & 2.360 & -4.34 & 4.70 & -7.35 & 7.97 & 2.170 \\
\hline Pulp \& Paper & 2.14 & -0.92 & 0.43 & -3.77 & 1.76 & 0.633 & 0.08 & -0.04 & 0.34 & -0.16 & -- \\
\hline Rolling \& Casting & 0.70 & 1.29 & -1.84 & 18.49 & -26.29 & -- & 5.22 & -7.42 & 74.72 & -106.28 & -- \\
\hline Steel Foundries & 3.22 & -0.02 & 0.01 & -2.95 & 0.92 & 0.098 & -0.15 & 0.05 & -20.46 & 6.35 & 0.28 \\
\hline Steel Pipes \& Tubes & 2.85 & -0.23 & 0.08 & -12.17 & 4.28 & 0.294 & -4.11 & 1.44 & -220.09 & 77.31 & 1.393 \\
\hline mean & 2.25 & -2.00 & $0.89^{\star}$ & -20.28 & $9.02^{*}$ & & -0.31 & $0.14^{\star}$ & -21.35 & $9.50^{*}$ & \\
\hline mean of negative & & -3.16 & $1.24^{*}$ & -34.02 & $13.40^{*}$ & 0.98 & -2.62 & $1.14^{*}$ & -56.49 & $24.54^{*}$ & 1.06 \\
\hline median & 2.35 & -0.23 & $0.10^{*}$ & -3.69 & $1.57^{*}$ & & -0.14 & $0.06^{*}$ & -7.35 & $3.13^{*}$ & \\
\hline median of negative & & -0.92 & $0.36^{*}$ & -8.99 & $3.54^{*}$ & 0.63 & -1.59 & $0.65^{\star}$ & -7.66 & $6.33^{*}$ & 0.93 \\
\hline \# negative & & 9 & & 9 & & & 8 & & 8 & & \\
\hline
\end{tabular}

*- mean (or median) of benefit/cost ratio are mean (or median) of savings divided by mean cost

not the mean (or median) of the individual ratios.

$\mathrm{B} / \mathrm{C}=$ benefit-cost ratio

ror $=$ rate of return

The table presents the cost savings realized from a new energy patent. Benefit-cost ratios and rates of return to R\&D are included. Savings are represented by negative numbers, and are in millions of 1987 dollars. The first half of the table shows the energy savings resulting from a new energy patent. The second half of the table shows the total variable cost savings due to a new energy patent. Note that most of the savings in variable costs is due to savings in energy consumption. 
Table 6 -- Rates of Decay and Diffusion for Knowledge

\begin{tabular}{|c|c|c|c|}
\hline Industry Group & decay & diffusion & year max. \\
\hline Aluminum & 0.25 & 0.03 & 3 \\
\hline Automotive & 0.54 & 0.03 & 1 \\
\hline Chemicals & 0.23 & 0.03 & 3 \\
\hline Copper & 0.05 & 0.01 & 16 \\
\hline Electrometallurgical & 0.10 & 0.03 & 8 \\
\hline Glass & 0.09 & 0.08 & 7 \\
\hline Iron Foundries & 0.06 & 1.50 & 1 \\
\hline Metal Coating & 0.67 & 2.33 & 0 \\
\hline Plastic Film \& Sheet & 1.27 & 0.02 & 0 \\
\hline Pulp \& Paper & 0.56 & 0.03 & 1 \\
\hline Rolling \& Casting & 0.22 & 0.01 & 3 \\
\hline Steel Foundries & 0.01 & 0.01 & 68 \\
\hline Steel Pipes \& Tubes & 0.01 & 0.18 & 16 \\
\hline mean & 0.31 & 0.33 & 9.77 \\
\hline median & 0.22 & 0.03 & 3.00 \\
\hline $\begin{array}{l}\text { max. year of mean } \\
\text { decay and diffusion }\end{array}$ & & & 1 \\
\hline $\begin{array}{l}\text { max. year of median } \\
\text { decay and diffusion }\end{array}$ & & & 3 \\
\hline
\end{tabular}

The chart presents the estimated discount rate and the rates of decay and diffusion. Year max. is the number of years until a patent has its greatest impact on energy savings, based on the rates of decay and diffusion for each industry. The final two rows are the year in which patents have their greatest impact, based on the mean and median rates of decay and diffusion. 


\section{Appendix Table 1A - Regression Results}

Dependent Variable: $E$

\begin{tabular}{lrrrrrrrr} 
Parameter (coefficient of) & Aluminum & Autos & Chemicals & Copper & Electrmtl. & Glass & Iron & Metal Coat \\
\hline$\alpha_{E}$ (constant) & -1.049 & 73.158 & -407.403 & 0.643 & 0.128 & 0.145 & 0.549 & 0.064 \\
& $(-3.571)$ & $(5.780)$ & $(-3.293)$ & $(12.203)$ & $(0.808)$ & $(3.138)$ & $(10.997)$ & $(3.342)$ \\
$\alpha_{E E}$ (energy prices) & -0.255 & 18.178 & -191.164 & -0.029 & -0.305 & -0.012 & 0.001 & -0.005 \\
& $(-3.405)$ & $(1.764)$ & $(-9.661)$ & $(-3.379)$ & $(-6.298)$ & $(-2.650)$ & $(0.063)$ & $(-3.210)$ \\
$\alpha_{E M}$ (materials prices) & 0.152 & -11.451 & 156.364 & 0.005 & 0.248 & 0.005 & -0.039 & 0.002 \\
& $(1.921)$ & $(-0.793)$ & $(7.447)$ & $(0.513)$ & $(4.972)$ & $(0.666)$ & $(-1.995)$ & $(0.979)$ \\
$\alpha_{E C}$ (lagged capital stock) & 0.132 & 0.026 & 0.236 & 0.084 & 0.261 & 0.014 & 0.092 & 0.009 \\
& $(2.103)$ & $(4.684)$ & $(9.284)$ & $(5.649)$ & $(9.877)$ & $(0.604)$ & $(5.208)$ & $(0.749)$ \\
$\varphi_{E \dot{C}}$ (change in C) & 0.552 & 0.017 & 0.093 & 0.262 & 0.116 & -0.031 & -0.075 & -0.009 \\
& $(3.217)$ & $(1.117)$ & $(1.216)$ & $(5.825)$ & $(1.568)$ & $(-0.928)$ & $(-1.555)$ & $(-0.300)$ \\
$\alpha_{E K E}$ (lagged $K_{E}$ ) & 15.418 & -8.824 & -301.914 & -5.655 & -60.302 & 8.176 & -13.640 & 0.120 \\
& $(0.657)$ & $(-3.180)$ & $(-3.499)$ & $(-3.154)$ & $(-7.868)$ & $(2.246)$ & $(-3.925)$ & $(1.892)$ \\
$\alpha_{E K O}$ (time trend) & 0.098 & -2.987 & 4.590 & -0.007 & 0.083 & -0.001 & 0.019 & 0.004 \\
& $(6.279)$ & $(-4.023)$ & $(1.407)$ & $(-1.468)$ & $(6.705)$ & $(-0.529)$ & $(4.226)$ & $(6.648)$ \\
& & & & & & & & \\
Durbin-Watson & 1.195 & 1.150 & 0.874 & 1.162 & 1.228 & 1.012 & 1.215 & 0.681 \\
estimated autocorrelation & 0.313 & 0.065 & 0.458 & 0.436 & 0.427 & 0.480 & 0.594 & 0.454 \\
\hline
\end{tabular}

\begin{tabular}{lrrrrrrrr}
\hline $\begin{array}{l}\text { Dependent Variable: } M \\
\text { Parameter (coefficient of) }\end{array}$ & Aluminum & Autos & Chemicals & Copper & Electrmtl. & Glass & Iron & Metal Coat \\
\hline$\alpha_{M}$ (constant) & 2.183 & 9817.352 & 3072.551 & 7.196 & 5.237 & 2.860 & 3.065 & 2.757 \\
& $(3.419)$ & $(18.498)$ & $(13.197)$ & $(37.152)$ & $(12.704)$ & $(10.089)$ & $(13.459)$ & $(9.011)$ \\
$\alpha_{E M}$ (energy prices) & 0.152 & -11.451 & 156.364 & 0.005 & 0.248 & 0.005 & -0.039 & 0.002 \\
& $(1.921)$ & $(-0.793)$ & $(7.447)$ & $(0.513)$ & $(4.972)$ & $(0.666)$ & $(-1.995)$ & $(0.979)$ \\
$\alpha_{M M}$ (materials prices) & -0.198 & -118.804 & -159.355 & -0.017 & -0.278 & -0.072 & 0.031 & -0.019 \\
& $(-2.317)$ & $(-2.161)$ & $(-6.760)$ & $(-2.105)$ & $(-5.034)$ & $(-3.762)$ & $(1.092)$ & $(-5.568)$ \\
$\alpha_{M C}$ (lagged capital stock) & 0.325 & -1.084 & 0.305 & 0.647 & 0.047 & -0.105 & 0.035 & -0.222 \\
& $(2.380)$ & $(-6.585)$ & $(6.541)$ & $(10.753)$ & $(0.652)$ & $(-0.743)$ & $(0.414)$ & $(-1.571)$ \\
$\varphi_{M \dot{C}}$ (change in C) & 0.174 & 0.480 & 0.775 & 0.140 & 0.841 & -0.219 & 0.927 & -0.240 \\
& $(0.560)$ & $(0.639)$ & $(5.448)$ & $(0.692)$ & $(3.875)$ & $(-0.959)$ & $(4.003)$ & $(-0.475)$ \\
$\alpha_{M K E}$ (lagged $K_{E}$ ) & -63.701 & 552.683 & -494.047 & -57.580 & -11.225 & 26.582 & -14.063 & 2.673 \\
& $(-1.257)$ & $(7.782)$ & $(-2.963)$ & $(-8.206)$ & $(-0.529)$ & $(1.191)$ & $(-0.823)$ & $(3.676)$ \\
$\alpha_{M K O}$ (time trend) & 0.085 & 82.672 & 35.452 & -0.005 & 0.037 & 0.028 & 0.075 & 0.024 \\
& $(3.127)$ & $(5.008)$ & $(7.485)$ & $(-0.310)$ & $(1.286)$ & $(2.046)$ & $(4.491)$ & $(4.319)$ \\
Durbin-Watson & & & & & & & & \\
estimated autocorrelation & 0.456 & 1.010 & 0.845 & 1.412 & 0.919 & 0.683 & 0.491 & 1.042 \\
\hline
\end{tabular}

Table is continued on the next page. 


\section{Appendix Table 1A - Regression Results}

\begin{tabular}{|c|c|c|c|c|c|c|c|c|}
\hline $\begin{array}{l}\text { Dependent Variable: } L \\
\text { Parameter (coefficient of) }\end{array}$ & Aluminum & Autos & Chemicals & Copper & Electrmtl. & Glass & Iron & Metal Coat \\
\hline \multirow{2}{*}{$\alpha_{0}$ (constant) } & 0.0013 & 30.8516 & 238.2705 & 0.1134 & 0.1056 & 0.3824 & 0.2060 & -0.3657 \\
\hline & $(0.034)$ & $(0.714)$ & (9.310) & $(7.000)$ & (3.136) & $(4.230)$ & $(11.497)$ & $(-9.269)$ \\
\hline \multirow[t]{2}{*}{$\alpha_{E E}$ (energy prices squared) } & 0.2546 & -18.1778 & 191.1638 & 0.0293 & 0.3049 & 0.0123 & -0.0012 & 0.0047 \\
\hline & $(3.405)$ & $(-1.764)$ & (9.661) & (3.379) & $(6.298)$ & $(2.650)$ & $(-0.063)$ & (3.210) \\
\hline \multirow[t]{2}{*}{$\alpha_{E M}$ (energy pr. $x$ mat. pr.) } & -0.1522 & 11.4506 & -156.3644 & -0.0046 & -0.2479 & -0.0049 & 0.0390 & -0.0017 \\
\hline & $(-1.921)$ & $(0.793)$ & $(-7.447)$ & $(-0.513)$ & $(-4.972)$ & $(-0.666)$ & (1.995) & $(-0.979)$ \\
\hline \multirow[t]{2}{*}{$\alpha_{M M}$ (mat. prices sqaured) } & 0.1978 & 118.8042 & 159.3547 & 0.0174 & 0.2779 & 0.0721 & -0.0310 & 0.0191 \\
\hline & (2.317) & $(2.161)$ & $(6.760)$ & (2.105) & (5.034) & (3.762) & $(-1.092)$ & $(5.568)$ \\
\hline \multirow[t]{2}{*}{$\alpha_{C}$ (lagged capital stock) } & 0.0363 & 0.0255 & 0.0344 & 0.0263 & 0.0052 & -0.2971 & -0.0448 & 0.1891 \\
\hline & (3.379) & (1.092) & (6.358) & $(5.961)$ & $(0.428)$ & $(-3.475)$ & $(-2.834)$ & $(5.940)$ \\
\hline \multirow[t]{2}{*}{$\alpha_{C C} \quad$ (lagged $C$ squared) } & 0.0010 & 0.0000 & 0.0000 & 0.0002 & 0.0011 & 0.0707 & -0.0084 & -0.0338 \\
\hline & $(0.872)$ & $(0.412)$ & $(1.376)$ & $(0.350)$ & $(1.552)$ & (2.932) & $(-5.559)$ & $(-3.797)$ \\
\hline \multirow{2}{*}{$\varphi_{c} \cdot($ change in $\mathrm{C})$} & 0.0021 & 0.1984 & -0.0207 & 0.0126 & -0.0303 & -0.4213 & -0.0312 & 0.6199 \\
\hline & $(0.083)$ & (2.293) & $(-0.712)$ & $(0.605)$ & $(-1.586)$ & $(-3.439)$ & $(-1.209)$ & (4.417) \\
\hline \multirow{2}{*}{$\varphi_{\dot{C} \dot{C}}$ (change in $C$ squared) } & 0.0031 & 0.0000 & 0.0000 & -0.0006 & 0.0047 & 0.2286 & 0.0805 & -0.1167 \\
\hline & $(0.516)$ & $(0.032)$ & (2.486) & $(-0.159)$ & $(0.661)$ & (3.285) & (2.915) & $(-0.681)$ \\
\hline \multirow[t]{2}{*}{$\gamma_{C C}$ (lagged $C \times$ change $C$ ) } & -0.0041 & -0.0001 & 0.0000 & 0.0084 & 0.0094 & 0.1959 & 0.0290 & 0.0853 \\
\hline & $(-0.635)$ & $(-2.435)$ & (2.601) & $(2.152)$ & $(2.526)$ & $(3.671)$ & (3.083) & (1.133) \\
\hline \multirow[t]{2}{*}{$\alpha_{K E} \quad\left(\right.$ lagged $\left.K_{E}\right)$} & -11.9259 & 6.5068 & -242.5746 & -2.5332 & -1.9097 & 53.9506 & 9.1465 & 1.6206 \\
\hline & $(-3.381)$ & $(0.731)$ & $(-11.809)$ & $(-3.081)$ & $(-0.445)$ & (4.139) & (2.895) & $(9.868)$ \\
\hline \multirow[t]{2}{*}{$\alpha_{K E K E}\left(\right.$ lagged $K_{E}$ squared $)$} & 738.3311 & 0.7477 & 88.2882 & 21.9601 & 68.2733 & 1162.1021 & -260.8286 & -1.9904 \\
\hline & (3.797) & $(0.615)$ & $(4.026)$ & $(1.744)$ & $(1.206)$ & $(1.665)$ & $(-3.984)$ & $(-10.501)$ \\
\hline \multirow[t]{2}{*}{$\alpha_{C K E} \quad\left(\right.$ lagged $C \times$ lagged $\left.K_{E}\right)$} & -2.3317 & -0.0054 & -0.0265 & -0.2608 & -0.5935 & -19.5926 & 3.1332 & 0.0021 \\
\hline & $(-2.524)$ & $(-1.324)$ & $(-1.947)$ & $(-1.945)$ & $(-1.539)$ & $(-2.438)$ & $(5.742)$ & $(0.039)$ \\
\hline \multirow[t]{2}{*}{$\gamma_{C K E}$ (change in $\mathrm{C} \times \operatorname{lag} K_{E}$ ) } & 1.9321 & 0.0329 & -0.0596 & 0.0716 & -2.4494 & -29.0614 & -4.4310 & -1.3487 \\
\hline & $(0.831)$ & (2.368) & $(-1.823)$ & $(0.115)$ & $(-2.295)$ & $(-3.637)$ & $(-2.768)$ & $(-4.397)$ \\
\hline \multirow{2}{*}{$\varphi_{\dot{K}_{E} \dot{K}_{E}}$ (change in $K_{E}$ squared) } & 3018.8109 & -14.7681 & -245.3610 & -4447.6423 & 5146.4256 & -1601.2408 & -367.5832 & 0.8787 \\
\hline & (1.806) & $(-1.599)$ & $(-1.886)$ & $(-3.803)$ & (1.934) & $(-2.427)$ & $(-0.840)$ & $(0.857)$ \\
\hline \multirow[t]{2}{*}{$\alpha_{K O}$ (time trend) } & 0.0057 & -3.4882 & 1.6797 & -0.0035 & -0.0041 & -0.0235 & 0.0012 & 0.0064 \\
\hline & $(2.771)$ & $(-1.449)$ & $(0.932)$ & $(-4.846)$ & $(-1.186)$ & $(-3.140)$ & $(0.453)$ & $(4.821)$ \\
\hline \multirow[t]{2}{*}{$\alpha_{\text {Коко }}$ (time trend squared) } & 0.0000 & -0.1049 & 0.0173 & -0.0001 & 0.0000 & 0.0001 & 0.0003 & -0.0001 \\
\hline & $(-0.671)$ & $(-2.398)$ & $(0.752)$ & $(-3.112)$ & $(0.162)$ & $(0.270)$ & $(1.943)$ & $(-4.719)$ \\
\hline \multirow[t]{2}{*}{$\alpha_{C K O} \quad$ (lagged $\mathrm{C} \times$ time trend $)$} & 0.0017 & 0.0009 & -0.0010 & -0.0005 & 0.0005 & 0.0064 & 0.0005 & -0.0006 \\
\hline & (3.662) & (1.285) & $(-2.851)$ & $(-1.607)$ & $(1.006)$ & $(1.371)$ & $(0.663)$ & $(-1.054)$ \\
\hline \multirow[t]{2}{*}{$\alpha_{K E K O}\left(\operatorname{lag} K_{E} \times\right.$ time trend $)$} & -0.7515 & 0.0643 & 1.0868 & 0.1085 & -0.0467 & -0.7353 & -0.3373 & -0.0217 \\
\hline & $(-4.338)$ & $(0.189)$ & $(1.657)$ & $(5.657)$ & $(-0.277)$ & $(-0.916)$ & $(-1.400)$ & $(-7.300)$ \\
\hline \multirow[t]{2}{*}{$\gamma_{C K O}$ (change in $\mathrm{C} \times$ trend) } & -0.0006 & -0.0045 & -0.0004 & -0.0034 & 0.0015 & 0.0130 & -0.0019 & -0.0217 \\
\hline & $(-0.539)$ & $(-1.672)$ & $(-0.977)$ & $(-2.855)$ & $(1.395)$ & (3.010) & $(-1.274)$ & $(-5.516)$ \\
\hline Durbin-Watson & 1.594 & 2.517 & 2.104 & 2.239 & 2.274 & 2.065 & 1.710 & 2.507 \\
\hline estimated autocorrelation & 0.097 & -0.182 & 0.069 & -0.088 & -0.057 & -0.060 & 0.212 & 0.160 \\
\hline Rate of Decay & 0.25 & 0.54 & 0.23 & 0.05 & 0.10 & 0.09 & 0.06 & 0.67 \\
\hline Rate of Diffusion & 0.03 & 0.03 & 0.03 & 0.01 & 0.03 & 0.08 & 1.50 & 2.33 \\
\hline $0.5 \log |\Sigma|$ & -3.387 & 4.042 & 3.894 & -4.671 & -3.597 & -5.124 & -4.688 & -5.967 \\
\hline
\end{tabular}

Table is continued on the next page. 


\section{Appendix Table 1A - Regression Results}

Dependent Variable: E

Parameter (coefficient of)

\begin{tabular}{lrrrrr} 
Parameter (coefficient of) & Plastics & Pulp & Roll \& Cast & Steel & Steel Pipes \\
\hline$\alpha_{E}$ (constant) & 40.857 & 0.649 & 401.392 & 0.061 & 0.117 \\
& $(1.009)$ & $(4.173)$ & $(2.754)$ & $(1.942)$ & $(4.042)$ \\
$\alpha_{E E}$ (energy prices) & -3.807 & -0.082 & -2.358 & -0.034 & -0.004 \\
& $(-1.222)$ & $(-5.483)$ & $(-0.178)$ & $(-5.641)$ & $(-0.440)$ \\
$\alpha_{E M}$ (materials prices) & -9.895 & 0.092 & -22.102 & 0.037 & 0.002 \\
& $(-2.658)$ & $(4.782)$ & $(-1.292)$ & $(4.700)$ & $(0.194)$ \\
$\alpha_{E C}$ (lagged capital stock) & 0.052 & 0.038 & 0.001 & 0.068 & 0.107 \\
& $(9.574)$ & $(3.302)$ & $(0.043)$ & $(12.528)$ & $(4.111)$ \\
\multicolumn{1}{c}{ (change in C) } & 0.017 & 0.034 & 0.226 & 0.049 & 0.056 \\
& $(0.444)$ & $(2.260)$ & $(2.523)$ & $(2.000)$ & $(1.362)$ \\
$\alpha_{E K E}$ (lagged $\left.K_{E}\right)$ & -262.507 & -30.205 & 128.389 & -2.091 & -1.406 \\
& $(-2.170)$ & $(-1.526)$ & $(1.454)$ & $(-7.192)$ & $(-3.022)$ \\
$\alpha_{E K O}$ (time trend) & 7.199 & -0.013 & -1.559 & 0.008 & 0.002 \\
& $(8.026)$ & $(-1.433)$ & $(-0.192)$ & $(5.469)$ & $(1.170)$ \\
& & & & & \\
Durbin-Watson & 0.943 & 0.235 & 0.801 & 1.292 & 0.937 \\
estimated autocorrelation & 0.137 & 0.681 & 0.441 & 0.302 & 0.444 \\
\hline
\end{tabular}

Table is continued on the next page. 


\section{Appendix Table 1A - Regression Results}

\begin{tabular}{|c|c|c|c|c|c|}
\hline $\begin{array}{l}\text { Dependent Variable: } L \\
\text { Parameter (coefficient of) }\end{array}$ & Plastics & Pulp & Roll \& Cast & Steel & Steel Pipes \\
\hline \multirow[t]{2}{*}{$\overline{\alpha_{0} \text { (constant) }}$} & 62.6583 & 0.0355 & -159.9307 & 0.5040 & 0.0833 \\
\hline & $(0.691)$ & $(1.296)$ & $(-2.286)$ & $(11.248)$ & (3.876) \\
\hline \multirow[t]{2}{*}{$\alpha_{E E}$ (energy prices squared) } & 3.8072 & 0.0824 & 2.3581 & 0.0336 & 0.0036 \\
\hline & $(1.222)$ & $(5.483)$ & $(0.178)$ & $(5.641)$ & $(0.440)$ \\
\hline \multirow[t]{2}{*}{$\alpha_{E M}$ (energy pr. $x$ mat. pr.) } & 9.8952 & -0.0923 & 22.1021 & -0.0375 & -0.0023 \\
\hline & (2.658) & $(-4.782)$ & $(1.292)$ & $(-4.700)$ & $(-0.194)$ \\
\hline \multirow[t]{2}{*}{$\alpha_{M M}$ (mat. prices sqaured) } & -13.6849 & 0.2101 & -89.0242 & 0.0452 & -0.0508 \\
\hline & $(-2.298)$ & (3.945) & $(-3.801)$ & $(1.635)$ & $(-2.540)$ \\
\hline \multirow[t]{2}{*}{$\alpha_{C} \quad$ (lagged capital stock) } & 0.0372 & -0.0059 & 0.1207 & -0.0962 & 0.2115 \\
\hline & (2.155) & $(-1.484)$ & (3.749) & $(-3.989)$ & (6.207) \\
\hline \multirow[t]{2}{*}{$\alpha_{C C} \quad$ (lagged C squared) } & 0.0000 & -0.0005 & 0.0000 & 0.0083 & 0.2169 \\
\hline & $(-4.409)$ & $(-3.539)$ & $(-3.962)$ & $(4.358)$ & (8.722) \\
\hline \multirow[t]{2}{*}{ (change in $\mathrm{C}$ ) } & -0.1529 & -0.0008 & 0.1227 & -0.3146 & -0.3686 \\
\hline & $(-1.397)$ & $(-0.198)$ & $(1.842)$ & $(-4.528)$ & $(-4.656)$ \\
\hline \multirow[t]{2}{*}{ (change in $\mathrm{C}$ squared) } & 0.0001 & -0.0013 & 0.0000 & 0.1014 & 0.1178 \\
\hline & (1.188) & $(-2.534)$ & $(-0.796)$ & (2.601) & (3.804) \\
\hline \multirow[t]{2}{*}{$\gamma_{C C} \quad($ lagged $\mathrm{C} \times$ change $\mathrm{C})$} & 0.0000 & -0.0003 & 0.0000 & 0.0623 & -0.0529 \\
\hline & $(0.280)$ & $(-0.540)$ & $(-1.603)$ & $(4.193)$ & $(-1.046)$ \\
\hline \multirow[t]{2}{*}{$\alpha_{K E} \quad$ (lagged $\left.K_{E}\right)$} & 340.5883 & 16.7128 & -323.6061 & 3.9652 & -2.9830 \\
\hline & $(0.804)$ & (2.608) & $(-3.573)$ & (2.555) & $(-4.781)$ \\
\hline \multirow{2}{*}{$\alpha_{K E K E} \quad\left(\right.$ lagged $K_{E}$ squared $)$} & -1589.3603 & -1872.8765 & -136.6591 & 18.9741 & 67.4851 \\
\hline & $(-2.017)$ & $(-4.114)$ & $(-4.530)$ & $(2.643)$ & $(8.223)$ \\
\hline \multirow[t]{2}{*}{$\alpha_{C K E} \quad\left(\right.$ lagged $\mathrm{C} \times$ lagged $\left.K_{E}\right)$} & 0.1099 & 1.9595 & 0.0903 & -0.6309 & -7.7173 \\
\hline & (2.456) & $(4.128)$ & $(4.283)$ & $(-3.200)$ & $(-8.477)$ \\
\hline \multirow[t]{2}{*}{$\gamma_{C K E}$ (change in $\mathrm{C} \times \operatorname{lag} K_{E}$ ) } & 0.4002 & 0.7149 & 0.0423 & -0.5178 & 2.1674 \\
\hline & $(1.190)$ & $(1.268)$ & $(1.188)$ & $(-0.544)$ & $(1.986)$ \\
\hline \multirow[t]{2}{*}{ (change in $K_{E}$ squared) } & 1293.7793 & 915.2964 & -626.2585 & -2146.1302 & -1738.6855 \\
\hline & (1.133) & $(0.717)$ & $(-5.977)$ & $(-2.505)$ & $(-9.162)$ \\
\hline \multirow[t]{2}{*}{$\alpha_{K O} \quad($ time trend) } & -3.0910 & 0.0056 & 24.1566 & -0.0140 & 0.0010 \\
\hline & $(-0.958)$ & $(2.080)$ & (3.597) & $(-3.334)$ & $(0.952)$ \\
\hline \multirow[t]{2}{*}{$\alpha_{\text {Коко }}$ (time trend squared) } & 0.0167 & -0.0004 & -0.4784 & 0.0003 & -0.0002 \\
\hline & $(0.550)$ & $(-3.701)$ & $(-3.194)$ & (2.292) & $(-8.215)$ \\
\hline \multirow[t]{2}{*}{$\alpha_{C K O} \quad($ lagged $\mathrm{C} \times$ time trend $)$} & 0.0005 & 0.0008 & -0.0060 & 0.0034 & -0.0028 \\
\hline & (1.495) & $(3.491)$ & $(-3.694)$ & $(3.507)$ & $(-6.994)$ \\
\hline \multirow[t]{2}{*}{$\alpha_{K E K O}\left(\operatorname{lag} K_{E} \times\right.$ time trend $)$} & -32.1977 & -1.6540 & 16.1162 & -0.1882 & 0.0573 \\
\hline & $(-3.563)$ & $(-4.068)$ & (3.563) & $(-2.548)$ & (6.393) \\
\hline \multirow[t]{2}{*}{$\gamma_{C K O}$ (change in $\mathrm{C} \times$ trend) } & 0.0061 & 0.0004 & -0.0010 & -0.0060 & -0.0020 \\
\hline & (3.106) & $(0.941)$ & $(-0.418)$ & $(-1.433)$ & $(-1.891)$ \\
\hline Durbin-Watson & 0.988 & 1.912 & 2.426 & 1.524 & 2.129 \\
\hline estimated autocorrelation & 0.193 & 0.307 & 0.102 & 0.109 & 0.127 \\
\hline Rate of Decay & 1.27 & 0.56 & 0.22 & 0.01 & 0.01 \\
\hline Rate of Diffusion & 0.02 & 0.03 & 0.01 & 0.01 & 0.18 \\
\hline $0.5 \log |\Sigma|$ & 3.177 & -3.934 & 4.141 & -5.050 & -4.844 \\
\hline
\end{tabular}

NOTE: $t$-stats in parentheses 


\section{Figure 1-- Industrial Energy Intensity}

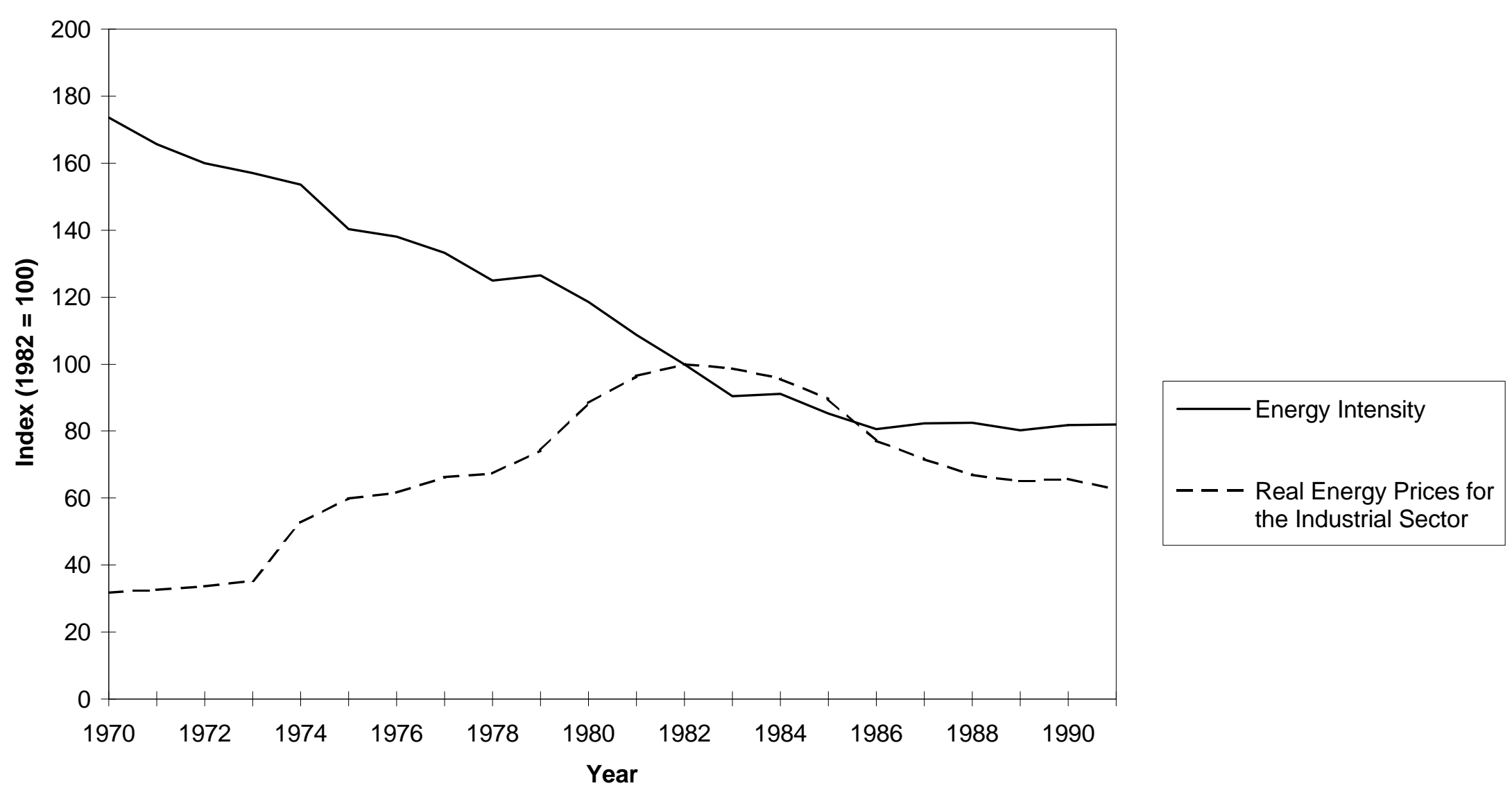

Energy intensity is Btu of energy per dollar of output. Energy prices are defined as dollars per million Btu of industrial energy consumption. Both are normalized so that $1982=100$. 
Figure 2 -- Energy Intensity and Energy Prices
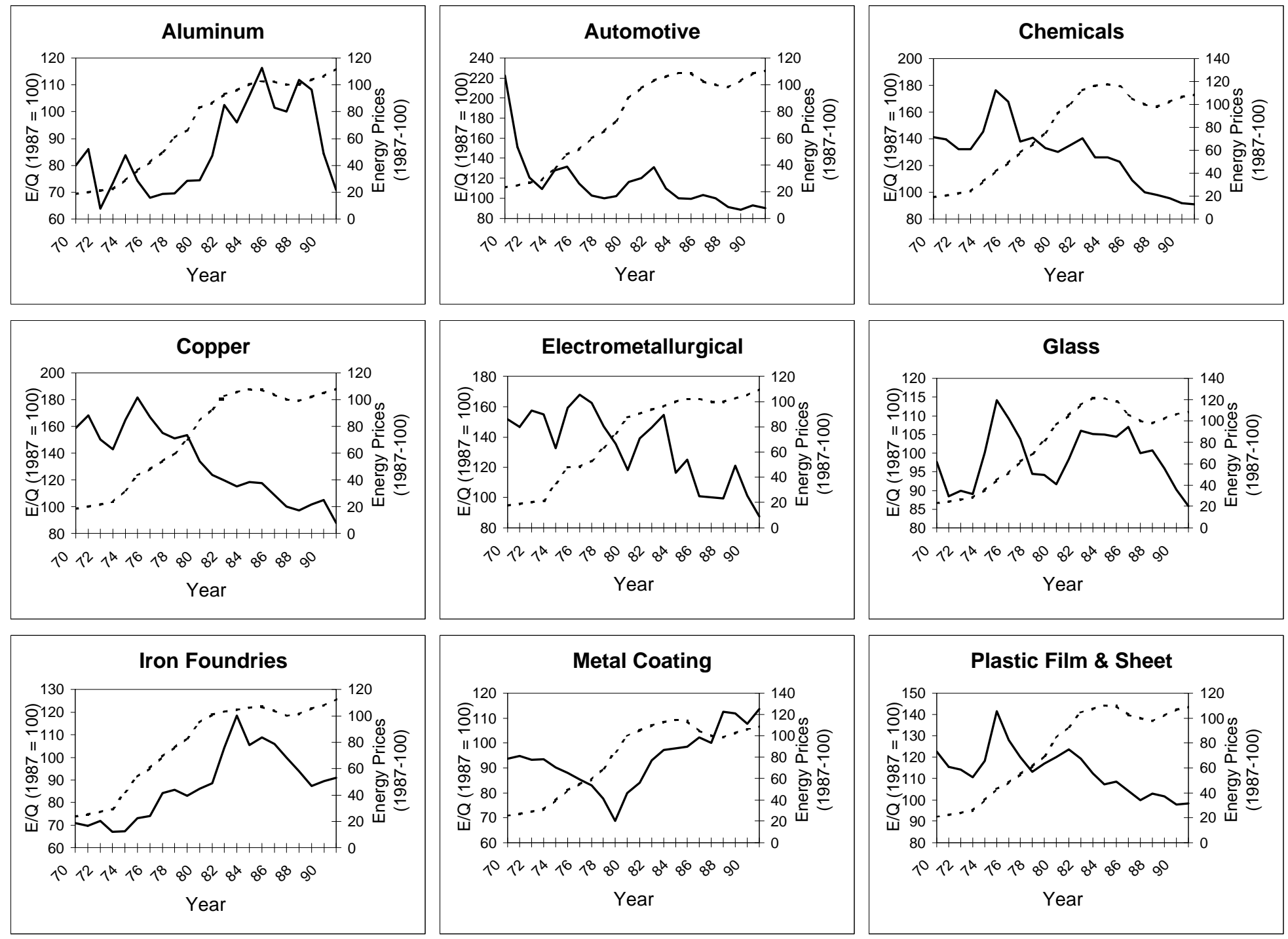

key: solid line = energy use/total output dashed line $=$ price of energy 
Figure 2 -- Energy Intensity and Energy Prices
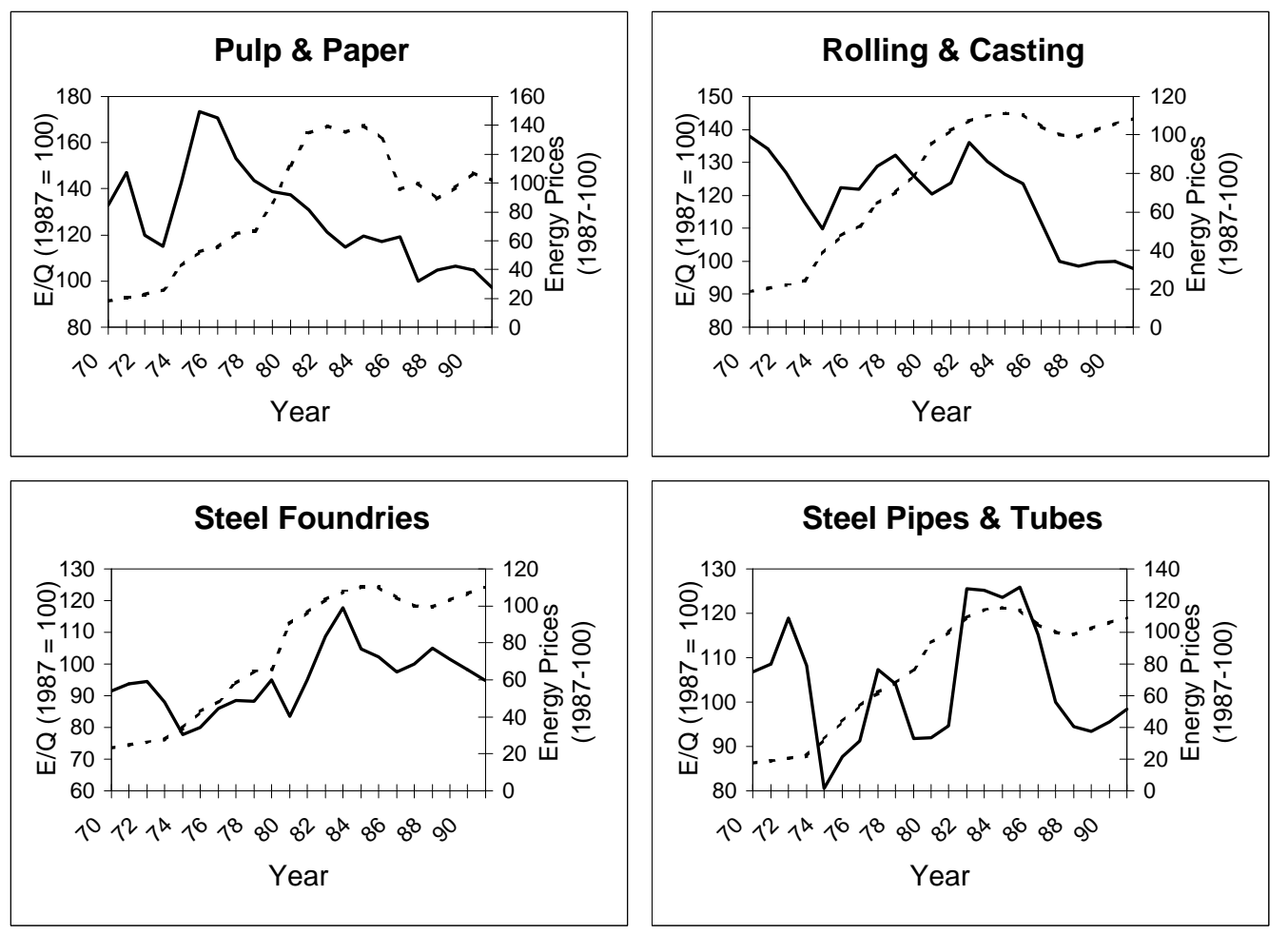

key: solid line = energy use/total output dashed line $=$ price of energy

Figure 2 plots energy prices and energy intensity for each of the 13 industries included in the paper. Energy intensity is defined as energy use divided by total output. The data for both trends are normalized so that 1982 equals 100 . The energy price data comes from the NBER Manufacturing Productivity Database, and is specific to each industry. Note that, for most industries, energy intensity and energy prices are negatively correlated. Also, for most industries, energy intensity continues to fall even after energy prices leveled off in the mid-1980's, suggesting that new technologies, and not just factor substitution, played an important role in the fall of industrial energy intensity. 
Figure 3 -- Effectiveness of Energy Patents Over Time
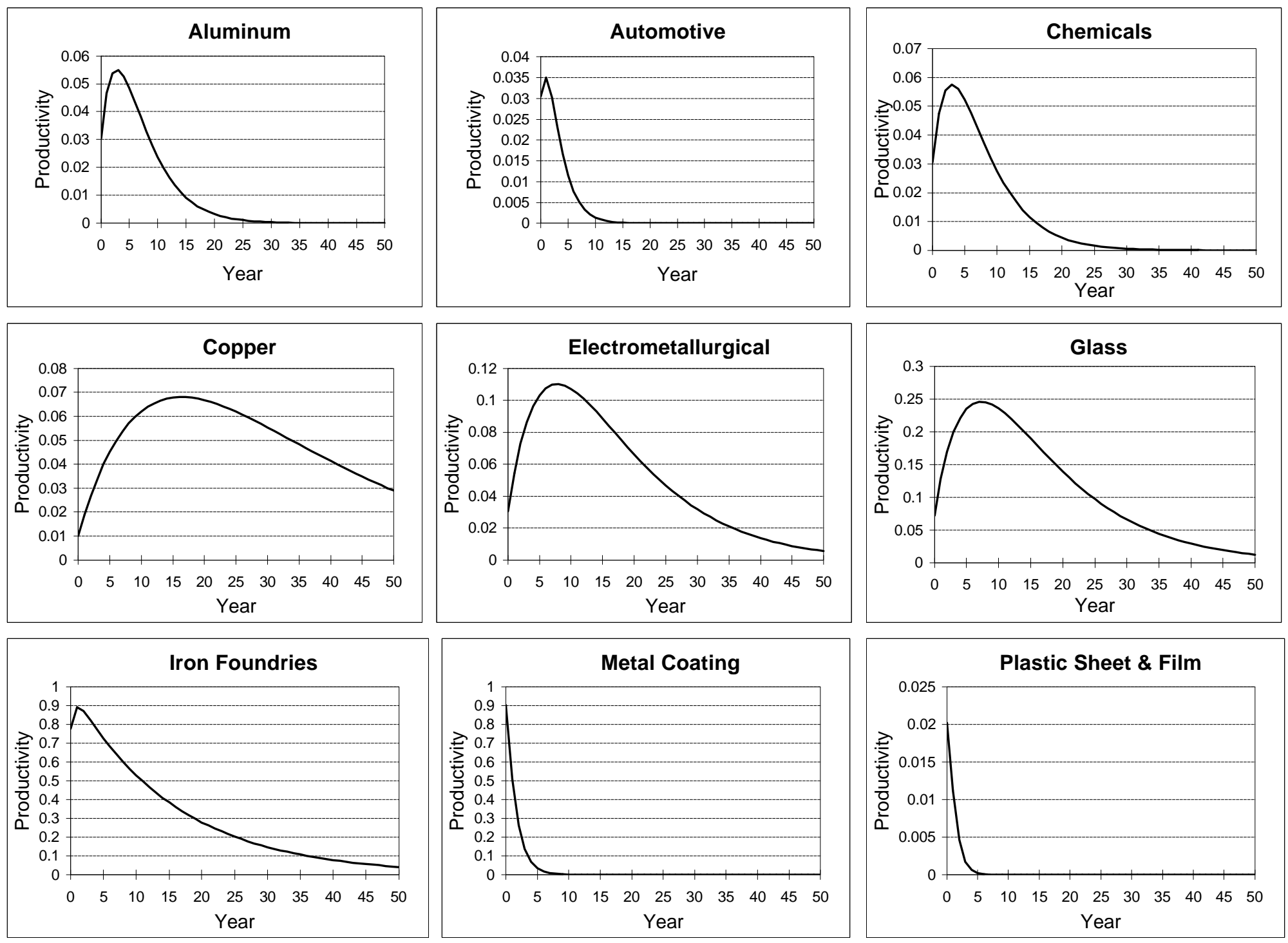
Figure 3 -- Effectiveness of Energy Patents Over Time
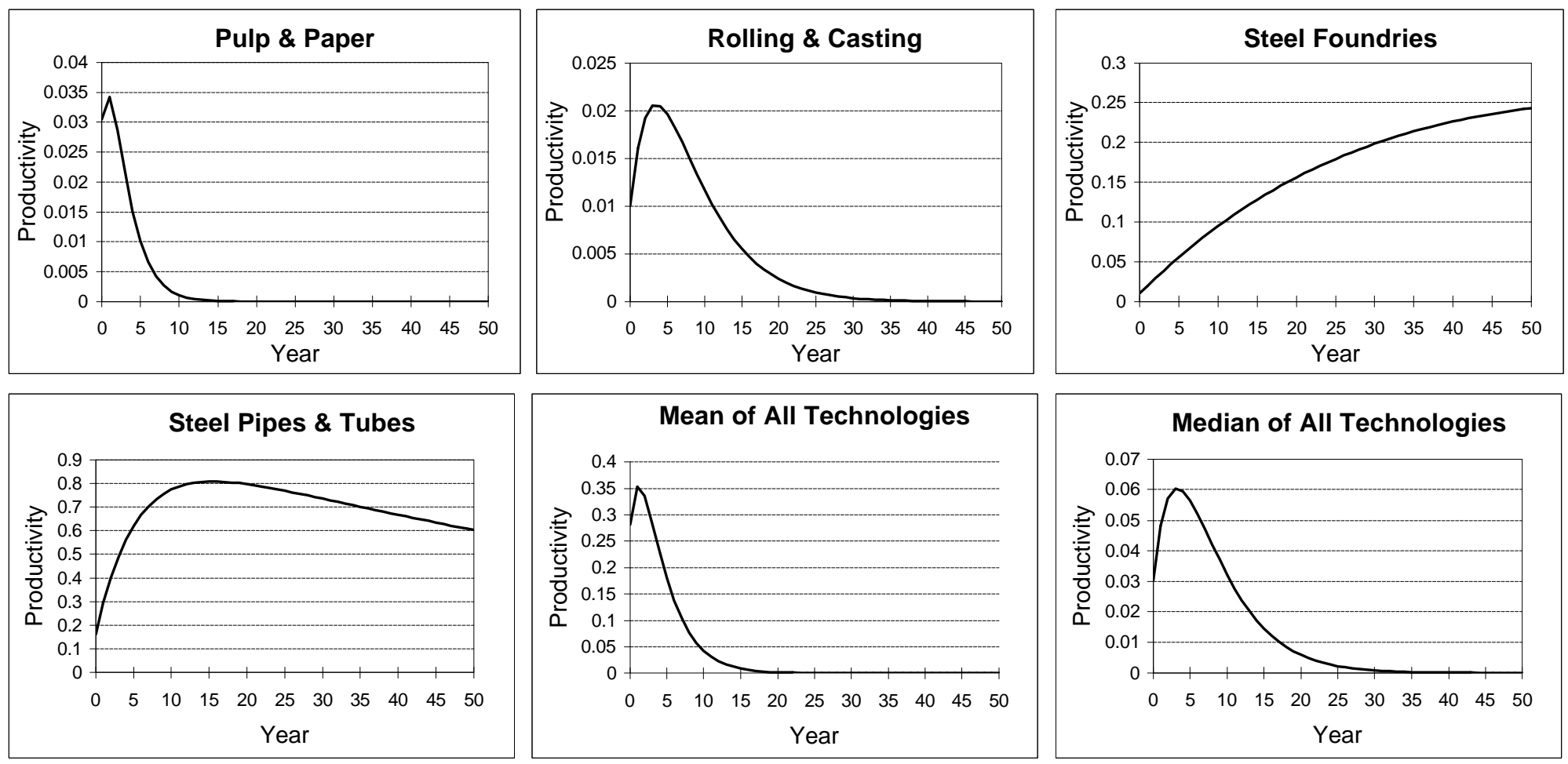

Figure 3 shows the weight given to a patent from year 0 in that year and over the next 50 years. The weight represents a patent's contribution to the stock of knowledge in a given year. As shown in equation (4), the weight is a combination of the decay rate and the rate of diffusion, and is equal to $e^{-\beta 1 s}\left(1-e^{-\beta 2(s+1)}\right)$, where $s$ is the age of the patent. Note that in most industries, a patent has its greatest impact within about three years after its initial application, as it takes time for the patent to diffuse through society. After this point, the decay rate dominates, and the impact of the patent on the stock of knowledge wanes, as it is replaced by newer patents which make it obsolete. 
Figure 4 -- Change in the Stock of Energy Knowledge Due to a $10 \%$ Energy Tax
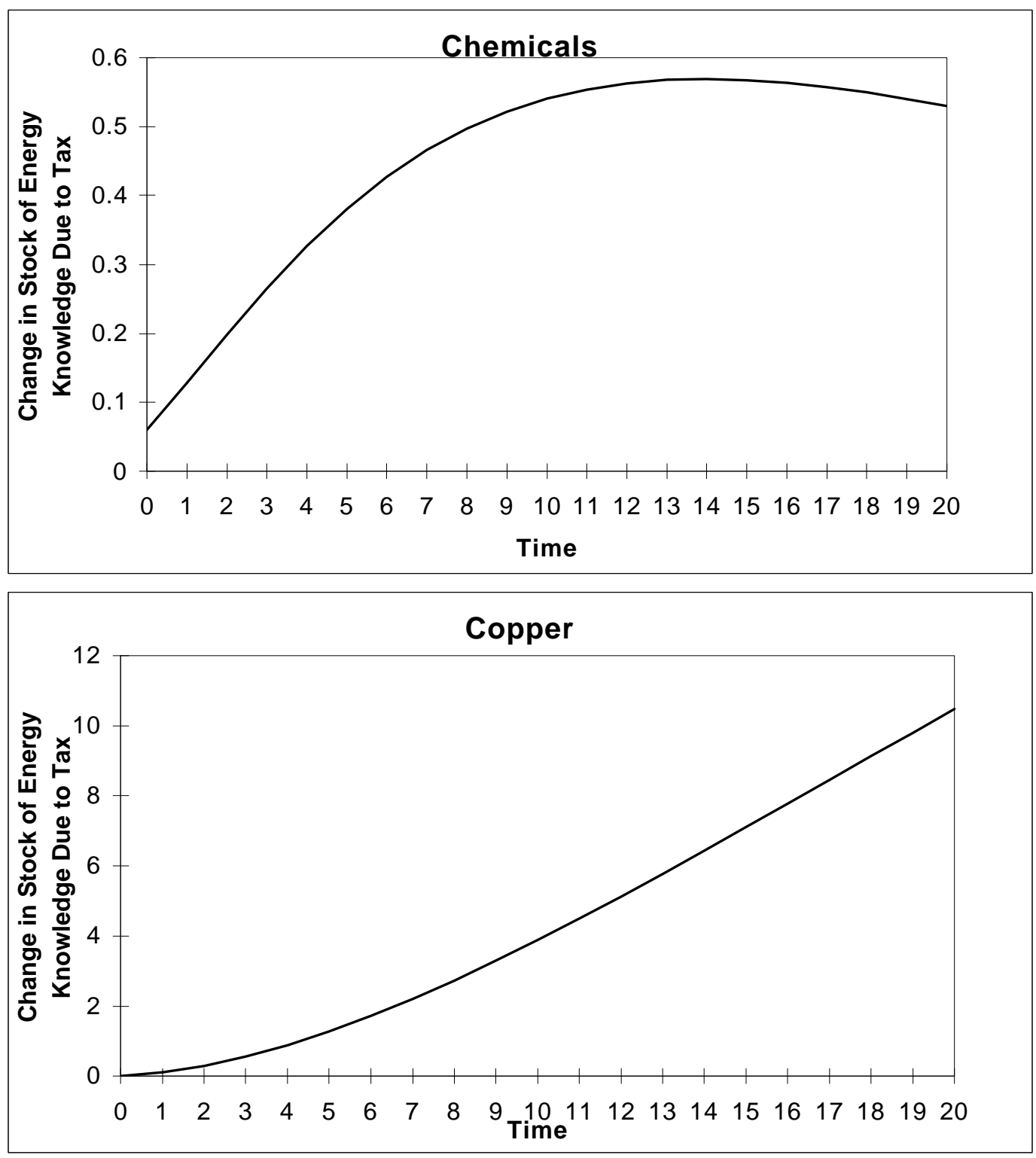

The figures show the change in the stock of energy knowledge due to the implementation of a ten percent energy tax in year 0 . Because of slow rates of diffusion and continuing incentives to invest in $R \& D$ throughout the 10 -year period, the stock tends to grow over time. As a result, induced innovation plays a much greater role than factor substitution in the long-run.

Figure is continued on the next page. 
Figure 4 -- Change in the Stock of Energy Knowledge Due to a $10 \%$ Energy Tax
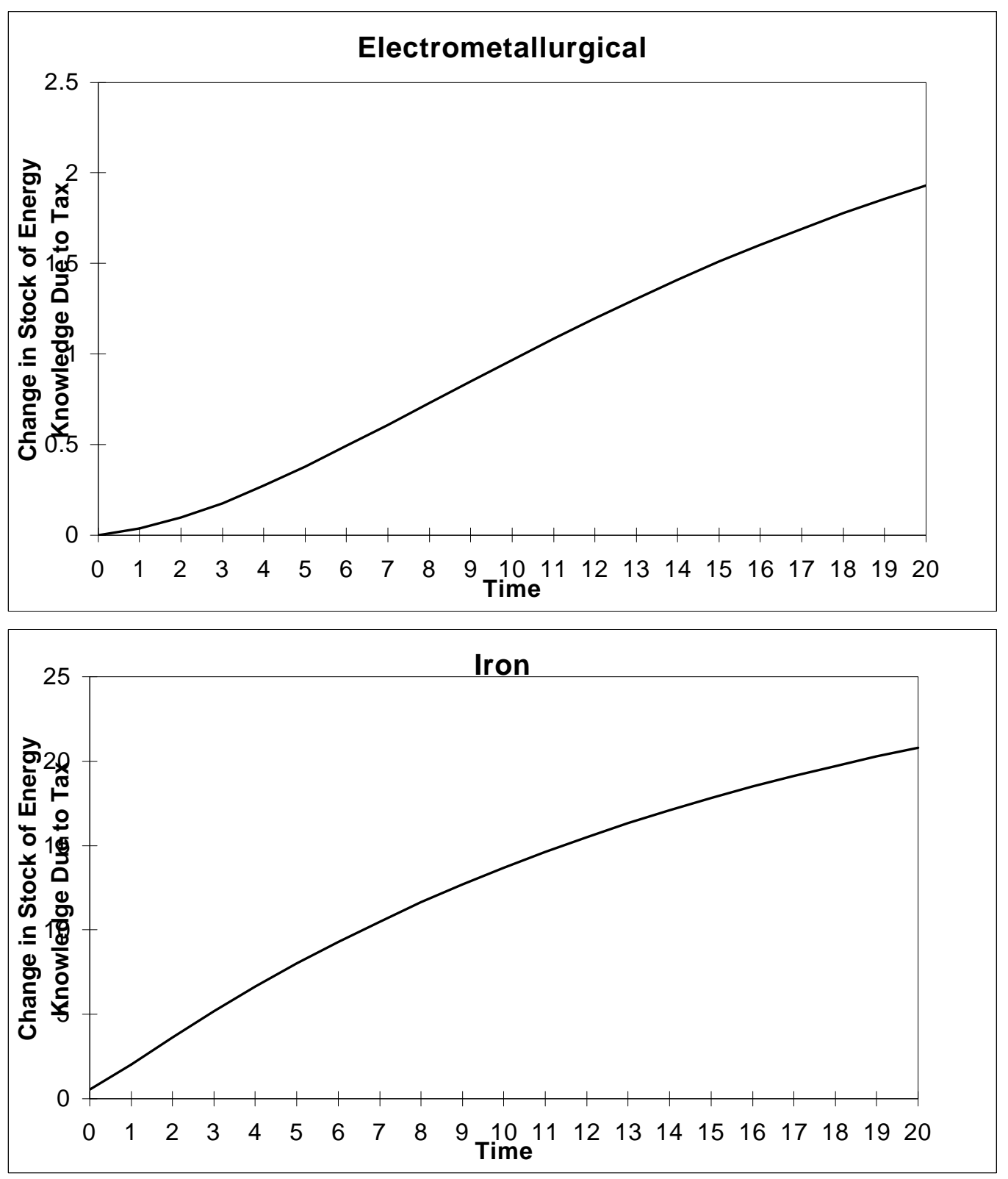

Thefigures show the change in the stock of energy knowledge due to the implementation of a ten percent energy tax in year 0 . Because of slow rates of diffusion and continuing incentives to invest in $R \& D$ throughout the 10 -year period, the stock tends to grow over time. As a result, induced innovation plays a much greater role than factor ubstitution in the long-run.

Figure is continued on the next page. 
Figure 4 -- Change in the Stock of Energy Knowledge Due to a $10 \%$ Energy Tax
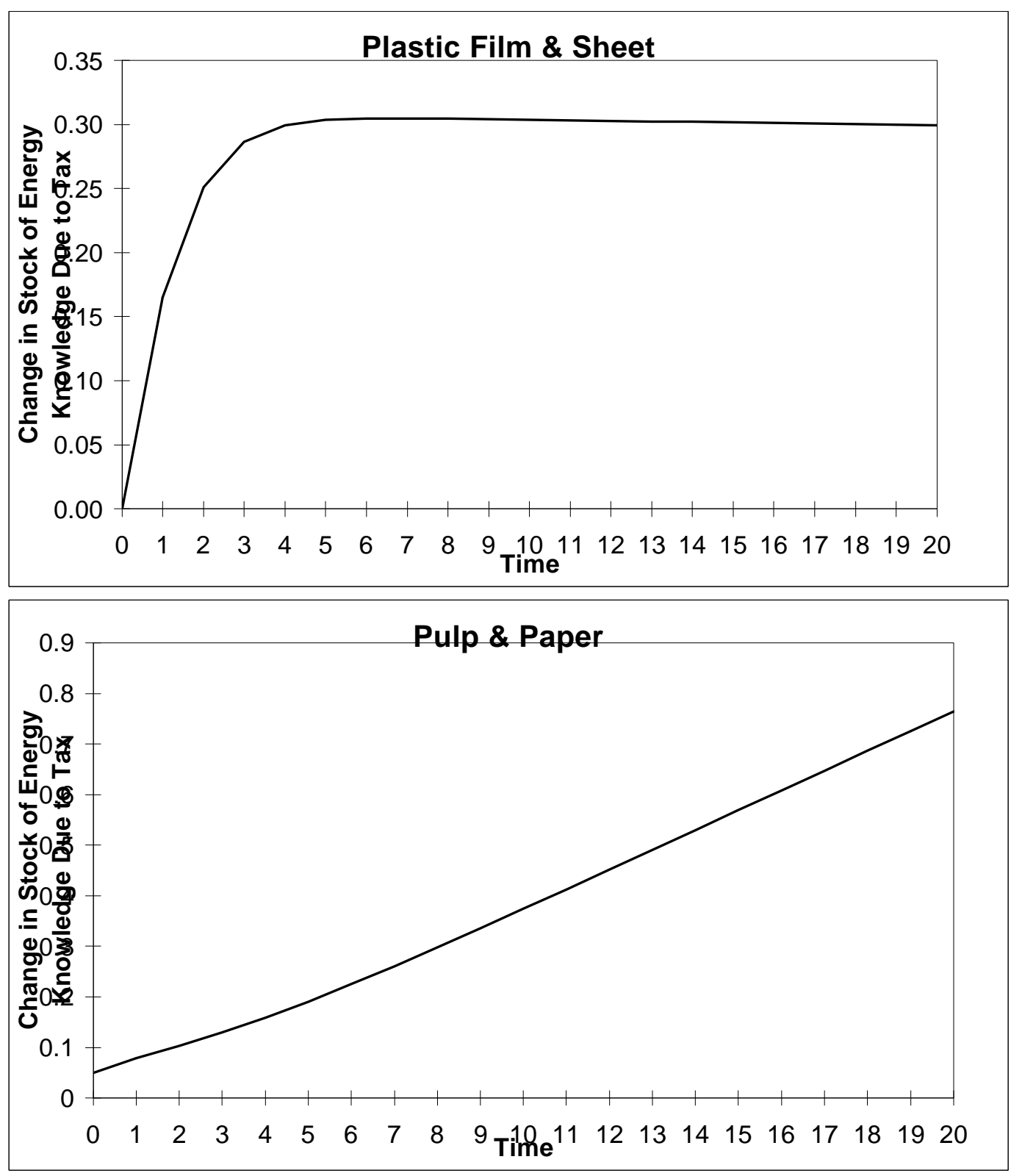

The figures show the change in the stock of energy knowledge due to the implementation of a ten percent energy tax in year 0. Because of slow rates of diffusion and continuing incentives to invest in R\&D throughout the 10-year period, the stock tends to grow over time. As a result, induced innovation plays a much greater role than factor substitution in the long-run.

Figure is continued on the next page. 
Figure 4 -- Change in the Stock of Energy Knowledge Due to a $10 \%$ Energy Tax
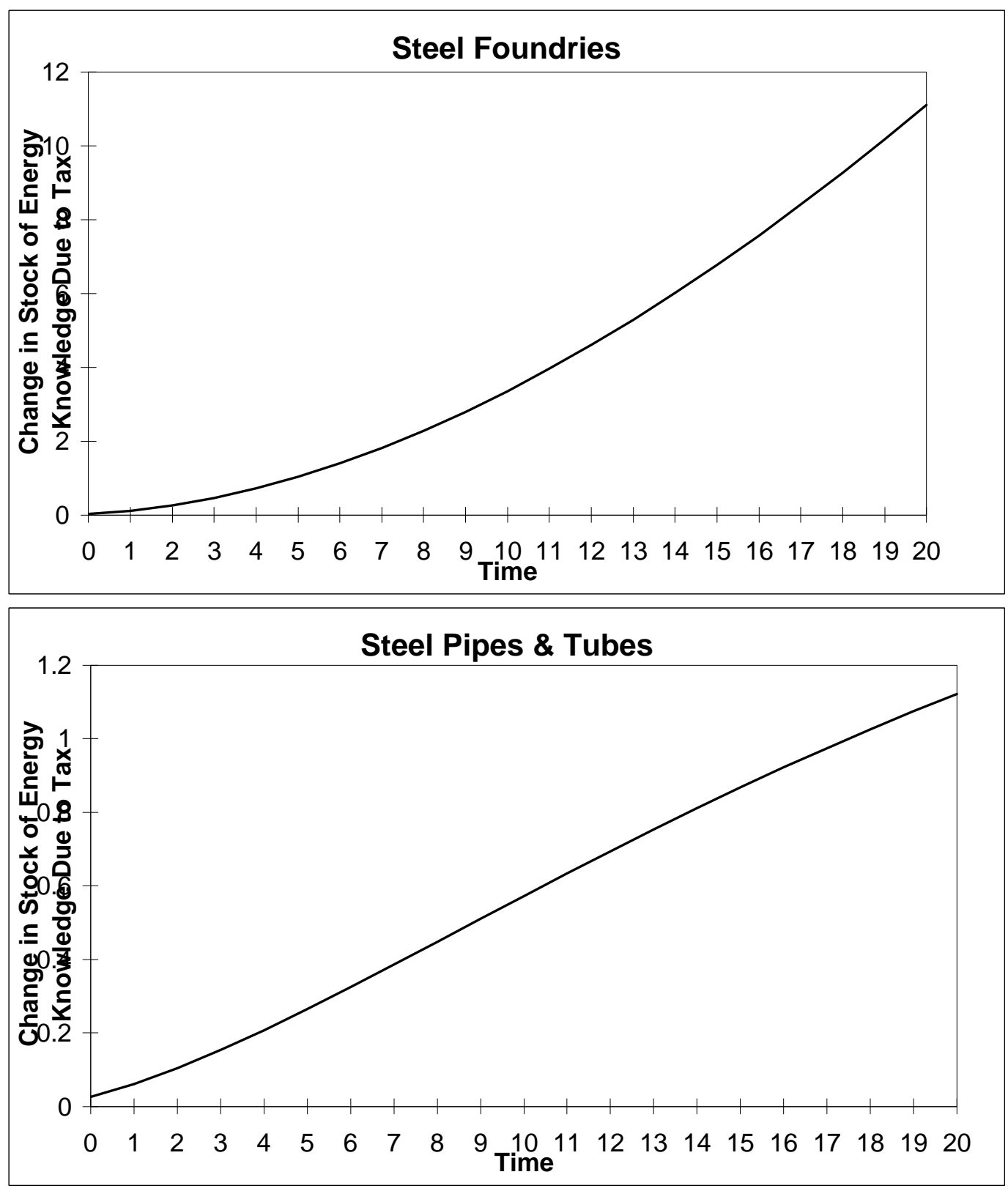

The figures show the change in the stock of energy knowledge due to the implementation of a ten percent energy tax in year 0 . Because of slow rates of diffusion and continuing incentives to invest in R\&D throughout the 10-year period, the stock tends to grow over time. As a result, induced innovation plays a much greater role than factor substitution in the long-run. 
Figure 5 -- Energy Savings from a 10\% Energy Tax millions of 1987 dollars
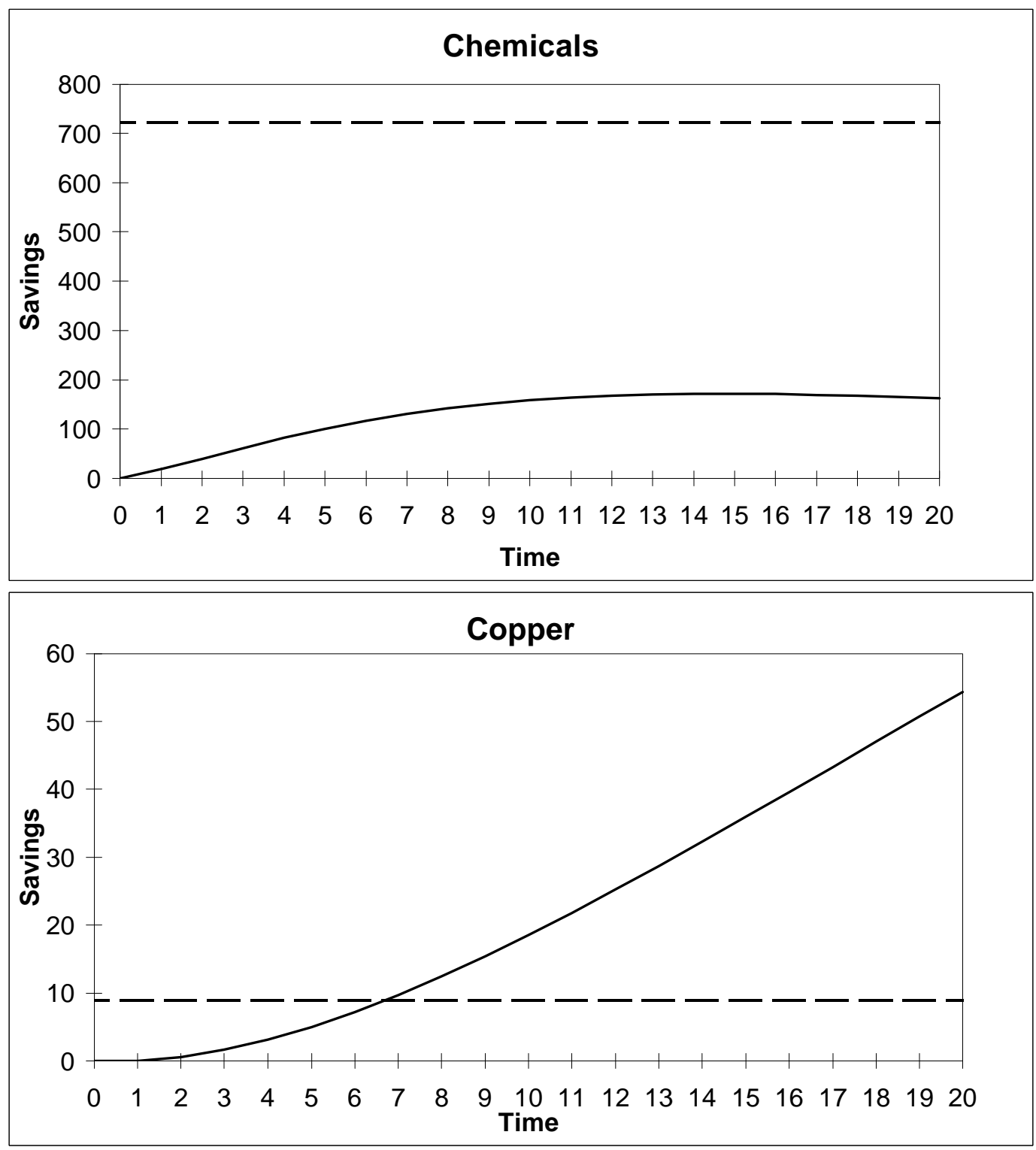

solid line: Energy savings due to induced technological change dashed line: Energy savings due to factor substitution

The figures show the annual energy savings after the implementation of a 10 percent energy tax in year 0 . Note that factor substitution contributes the most to total savings immediately after the tax is imposed, but the effect of induced technological change soon becomes greater, as the effects of innovation are cummulative.

Figure is continued on the next page. 
Figure 5 -- Energy Savings from a 10\% Energy Tax millions of 1987 dollars
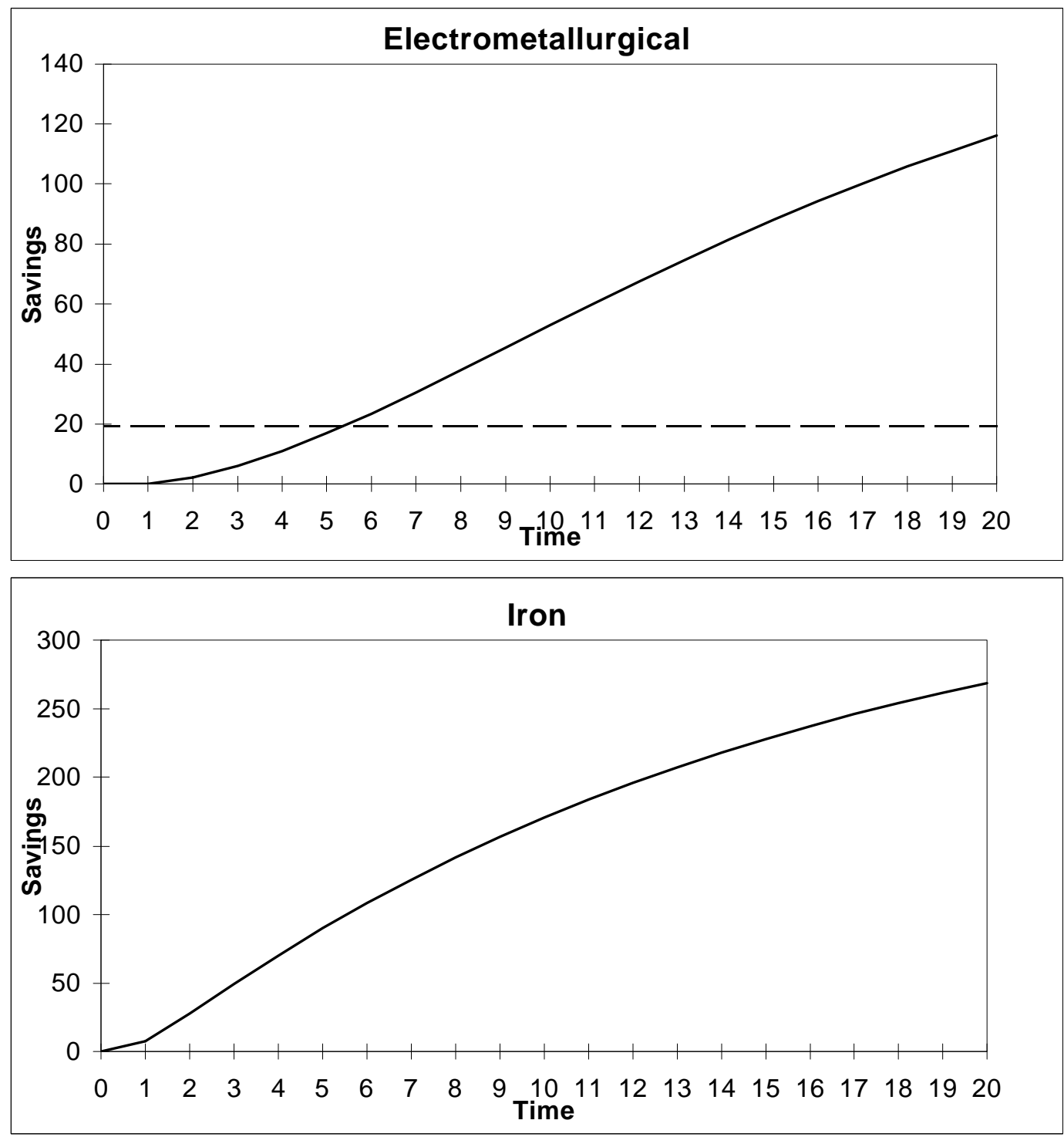

solid line: Energy savings due to induced technological change dashed line: Energy savings due to factor substitution

The figures show the annual energy savings after the implementation of a 10 percent energy tax in year 0 . Note that factor substitution contributes the most to total savings immediately after the tax is imposed, but the effect of induced technological change soon becomes greater, as the effects of innovation are cummulative.

Figure is continued on the next page. 
Figure 5 -- Energy Savings from a 10\% Energy Tax millions of 1987 dollars
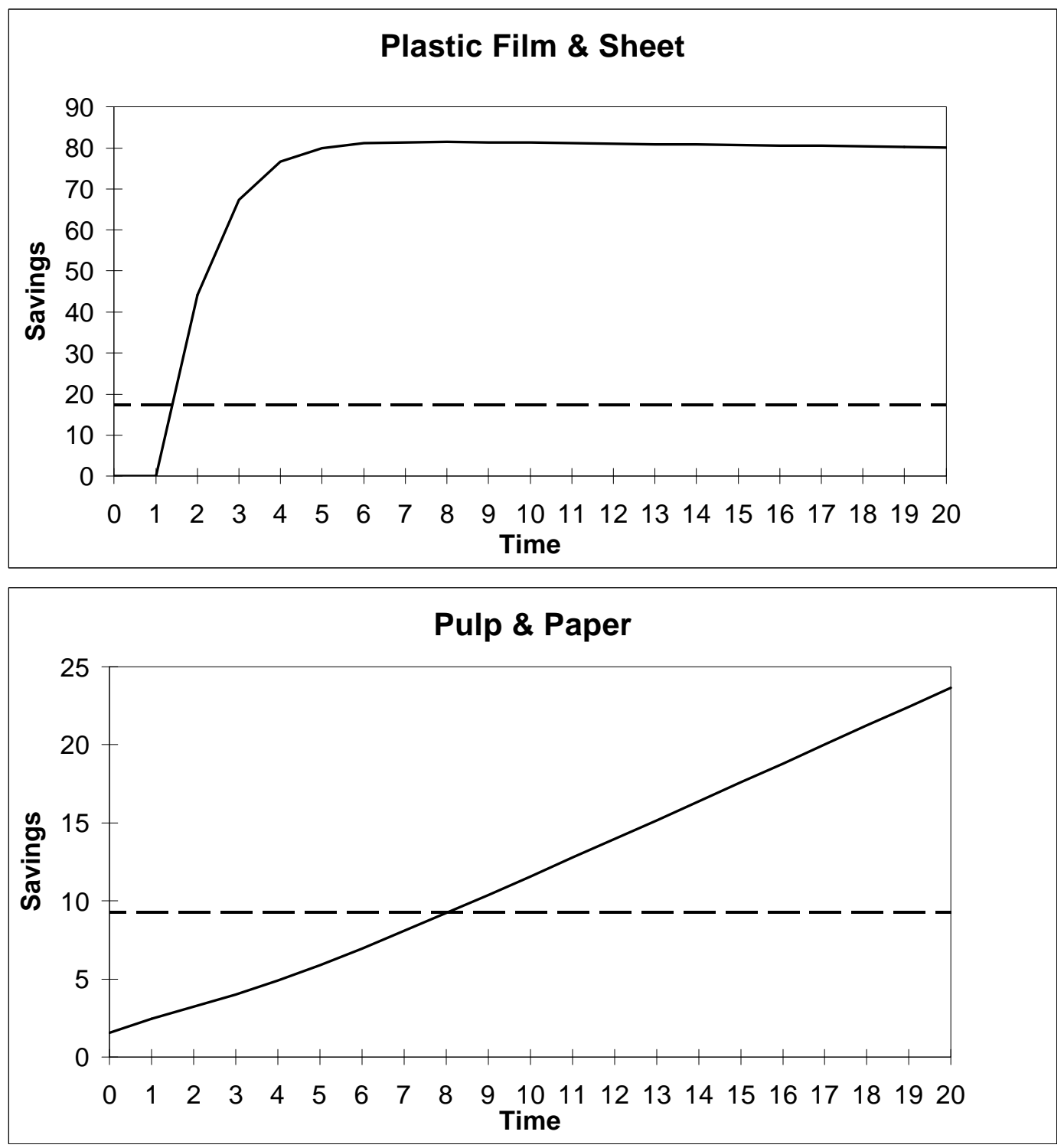

solid line: Energy savings due to induced technological change dashed line: Energy savings due to factor substitution

The figures show the annual energy savings after the implementation of a 10 percent energy tax in year 0 . Note that factor substitution contributes the most to total savings immediately after the tax is imposed, but the effect of induced technological change soon becomes greater, as the effects of innovation are cummulative.

Figure is continued on the next page. 
Figure 5 -- Energy Savings from a 10\% Energy Tax millions of 1987 dollars
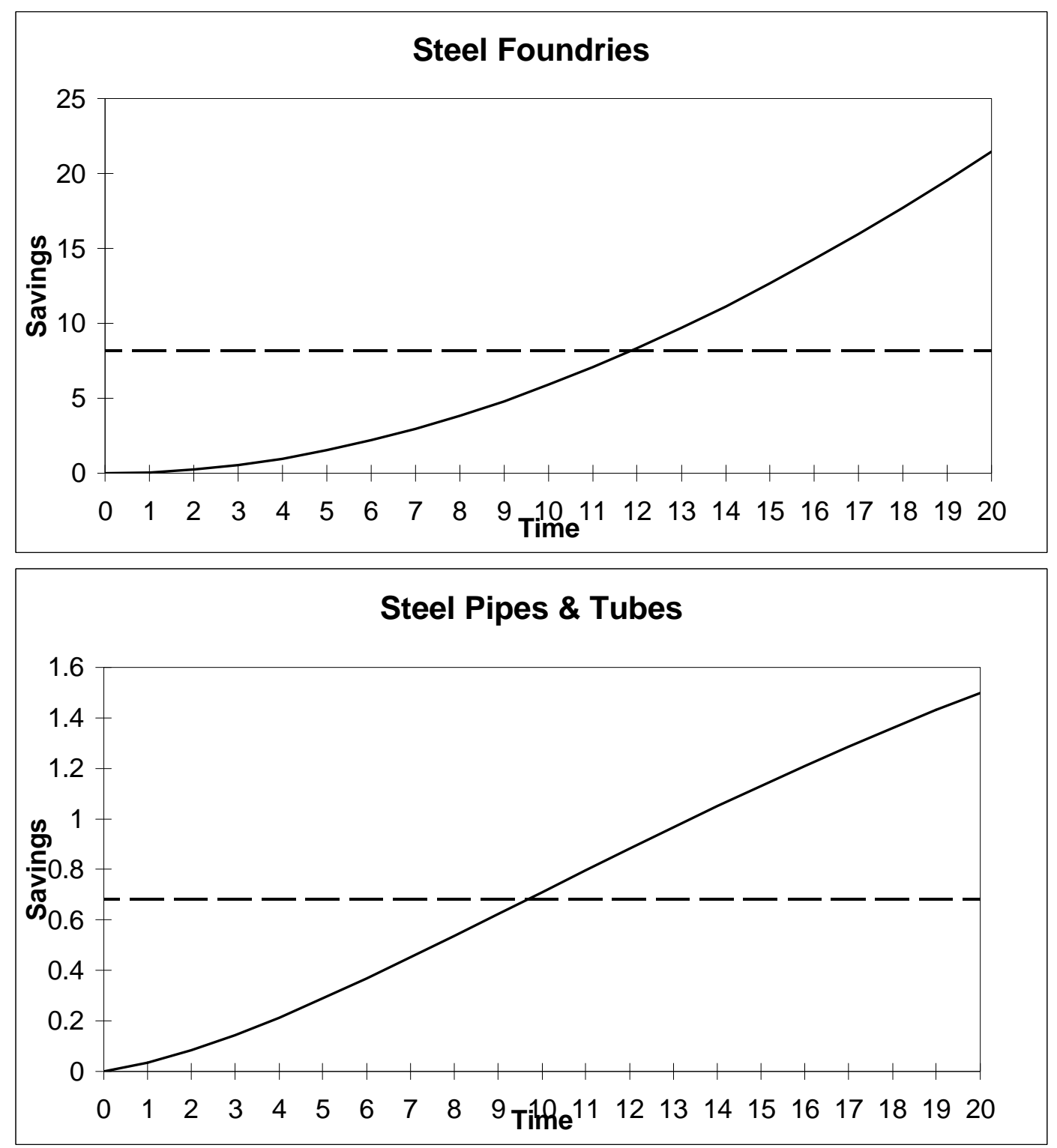

solid line: Energy savings due to induced technological change dashed line: Energy savings due to factor substitution

The figures show the annual energy savings after the implementation of a 10 percent energy tax in year 0 . Note that factor substitution contributes the most to total savings immediately after the tax is imposed, but the effect of induced technological change soon becomes greater, as the effects of innovation are cummulative. 